\title{
Requisitos de Uniformidad para manuscritos enviados a revistas biomédicas: Redacción y preparación de la edición de una publicación biomédica
}

\author{
Actualizado en Abril de 2010 \\ Pautas de publicación: patrocinio, autoría y responsabilidad \\ Comité Internacional de Editores* de Revistas Médicas (ICMJE)
}

Última revisión de la traducción: 8 de Junio de 2011

\begin{abstract}
Traducción al español del Uniform Requirements for Manuscripts Submitted to Biomedical Journals (Updated April 2010), cuya versión oficial se encuentra en http://www.ICMJE.org. El

ICMJE revisa periódicamente los Requisitos de Uniformidad y por lo tanto puede que esta traducción no refleje la versión oficial vigente.
\end{abstract}

La traducción inicial ha sido realizada por el Servei de Traduccions i Revisions de Textos de la Universitat Autónoma de Barcelona (UAB). La traducción de esta Actualización ha sido realizada por el Dr. Jaume Juan Castelló. ${ }^{1}$ Las traducciones han sido revisadas por los profesores Joseph M. Domenech Massons, ${ }^{2}$ Jaume Juan

Castelló $^{1}$ y Miguel Porta Serra. ${ }^{3}$

La traducción ha sido patrocinada por los Estudios de Formación Continuada a distancia en Metodología de la investigación: Diseño y Estadística en Ciencias de la

Salud de la UAB y puede descargarse libremente en http://www.metodo.uab.cat. Esta traducción se revisa periódicamente a partir de las sugerencias que se reciben en la dirección: requisitos@metodo.uab.cat

* Teniendo en cuenta las múltiples acepciones y usos del término inglés editor en el mundo académico anglosajón (por ejemplo, editors, editor in chief), esta traducción utiliza también el término español "editor" para designar a la persona que dirige una revista médica.

1 Facultat de Filologia, Universitat de Barcelona. Barcelona (Spain).

2 Laboratori d'Estadística Aplicada, Universitat Autónoma de Barcelona. Barcelona (Spain).

3 Facultat de Medicina, Universitat Autónoma de Barcelona. Barcelona (Spain). 


\section{Propósito}

I. A. Sobre los Requisitos de Uniformidad

I. B. Posibles usuarios de los Requisitos de Uniformidad

I. C. Cómo utilizar los Requisitos de Uniformidad

\section{Consideraciones éticas en la realización y en la comunicación de una investigación}

II. A. Autoría y contribuciones

II. A.1. Autores

II. A.2. Colaboradores que aparecen en los Agradecimientos

II. B. Dirección

II. B.1. La función del editor (director)

II. B.2. Libertad editorial

II. C. Evaluación por pares

II. D. Conflictos de intereses

II. D.1. Posibles conflictos de intereses relacionados con los compromisos de los autores

II. D.2. Posibles conflictos de intereses relacionados con la financiación del proyecto

II. D.3. Posibles conflictos de intereses relacionados con los compromisos de los editores, del personal de la revista o de los revisores

II. E. Privacidad y confidencialidad

II. E.1. Pacientes y participantes en el estudio

II. E.2. Autores y revisores

II. F. Protección de las personas y de los animales que participan en la investigación

\section{Aspectos sobre edición y publicación en revistas biomédicas}

III. A. Obligación de publicar los estudios con resultados negativos

III. B. Correcciones, Retractaciones y Notas de reserva

III. C. Derechos de autor 
III. D. Publicaciones solapadas

III. D.1. Envíos duplicados

III. D.2. Publicación redundante

III. D.3. Publicación secundaria aceptable

III. D.4. Manuscritos concurrentes basados en el mismo estudio

III. D.4.a. Discrepancias en el análisis o en la interpretación

III. D.4.b. Discrepancias en los métodos o resultados

III. D.5. Manuscritos concurrentes basados en la misma base de datos

III. E. Cartas de los lectores

III. F. Suplementos, números monográficos y series especiales

III. G. Publicación electrónica

III. H. Publicidad

III. I. Revistas médicas y medios de comunicación

III. J. Registro obligatorio de los ensayos clínicos

\section{Preparación y envío del manuscrito}

IV. A. Cómo preparar un manuscrito para enviarlo a una revista biomédica

IV. A.1.a. Principios generales

IV. A.1.b. Directrices para la presentación de estudios con diseños específicos

IV. A.2. Portada

IV. A.3. Declaración de conflictos de intereses

IV. A.4. Resumen

IV. A.5. Introducción

IV. A.6. Métodos

IV. A.6.a. Selección y descripción de los participantes

IV. A.6.b. Información técnica

IV. A.6.c. Estadística

http://scielo.sld.cu 
IV. A.7. Resultados

IV. A.8. Discusión

IV. A.9. Referencias bibliográficas

IV. A.9.a. Consideraciones generales sobre las referencias

IV. A.9.b. Estilo y formato de una referencia

IV. A.10. Tablas

IV. A.11. Ilustraciones (figuras)

IV. A.12. Leyendas de las ilustraciones

IV. A.13. Unidades de medida

IV. A.14. Abreviaturas y símbolos

IV. B Envío del manuscrito a la revista

\section{Referencias}

A. Referencias citadas en este documento

B. Otras fuentes de información relacionadas con revistas biomédicas

VI. Sobre el Comité Internacional de Editores de Revistas Biomédicas

VII. Autores de los Requisitos de Uniformidad

VIII. Uso, distribución y traducción de los Requisitos de Uniformidad

IX. Preguntas

\section{Apéndice}

Requisitos de uniformidad para manuscritos enviados a revistas biomédicas: Ejemplos de referencias

Artículos de Revistas

Libros y otras Monografías

Otros tipos de publicaciones

Trabajos no publicados

Material electrónico

http://scielo.sld.cu 


\section{Propósito}

\section{A. Sobre los Requisitos de Uniformidad}

En el año 1978 un grupo reducido de editores (directores) de revistas de medicina general se reunió de manera informal en Vancouver (Columbia Británica) para establecer los requisitos básicos que debían cumplir los manuscritos que se presentaban a sus revistas. Este grupo se dio a conocer con el nombre de Grupo Vancouver. Los Requisitos de Uniformidad de los manuscritos, entre los que se incluyen los formatos de las referencias bibliográficas elaborados por la National Library of Medicine (NLM) de los EE. UU., fueron publicados por primera vez en 1979. El Grupo Vancouver se fue ampliando y ha dado origen al actual Comité Internacional de Editores de Revistas Médicas (International Committee of Medical Journal Editors, ICMJE), que se reúne una vez al año. Progresivamente el ICMJE ha ido ampliando sus campos de acción y en la actualidad incluye también los principios éticos relacionados con la publicación en revistas biomédicas.

El ICMJE ha realizado múltiples ediciones de los Requisitos de Uniformidad de Manuscritos enviados a Revistas Biomédicas. Con el tiempo, han ido apareciendo nuevos planteamientos que van más allá de la simple preparación del manuscrito y que han dado lugar al desarrollo de una serie de Disposiciones sobre política editorial. El documento completo de los Requisitos de Uniformidad fue revisado en 1997; los apartados fueron actualizados en mayo de 1999 y en mayo de 2000. En mayo de 2001, el ICMJE revisó los apartados correspondientes a los posibles conflictos de intereses. En el año 2003, el Comité revisó y reorganizó todo el documento, y añadió al cuerpo del texto las mencionadas Disposiciones. La actual revisión fue preparada por el Comité en el año 2010.

El contenido completo de los Requisitos de Uniformidad de Manuscritos enviados a Revistas Biomédicas puede publicarse con fines educativos y sin ánimo de lucro, sin necesidad de atender a los derechos de autor; el Comité fomenta la distribución de este material.

Pedimos a las revistas que utilizan estos Requisitos de Uniformidad que indiquen, en las instrucciones para los autores, que sus normas son conformes a los Requisitos de Uniformidad de este Comité y que citen esta versión. Las revistas que deseen figurar en http://www.ICMJE.org entre el listado de publicaciones que siguen los Requisitos de Uniformidad deben ponerse en contacto con la oficina de la secretaría del ICMJE.

El ICMJE es un grupo restringido de trabajo de revistas de medicina general, no una organización de libre asociación. Ocasionalmente, el ICMJE aceptará un nuevo miembro o invitado cuando considere que la nueva revista u organización puede aportar una nueva perspectiva que sea necesaria y no esté representada entre los miembros del actual comité. Se consideran organizaciones de libre asociación para editores de publicaciones biomédicas y afines organizaciones tales como la World Association of Medical Editors (http://www.WAME.org), el Council of Science Editors (http://www.councilofscienceeditors.org), y la European Association of Science Editors (http://www.ease.org.uk).

\section{B. Posibles usuarios de los Requisitos de Uniformidad}

Los Requisitos de Uniformidad fueron creados por el ICMJE fundamentalmente para ayudar a los autores y editores en su tarea conjunta de elaborar y difundir artículos sobre estudios biomédicos que sean precisos, claros y fácilmente asequibles. Los

http://scielo.sld.cu 
apartados iniciales tratan sobre los principios éticos del proceso de evaluación, mejora y publicación de manuscritos en revistas biomédicas, y de las relaciones entre editores y autores, revisores y medios de comunicación. Los últimos apartados tratan de los aspectos más técnicos de la preparación y presentación de manuscritos. El ICMJE cree que este documento, en su conjunto, es de interés tanto para autores como para editores.

Los Requisitos de Uniformidad pueden proporcionar también a otros muchos posibles interesados -revisores o evaluadores, editoriales, medios de comunicación, pacientes y familiares, y lectores en general- puntos de vista útiles en el proceso de autoría y edición de textos biomédicos.

\section{C. Cómo utilizar los Requisitos de Uniformidad}

Los Requisitos de Uniformidad establecen los principios éticos que deben observarse en el desarrollo de una investigación y en su informe escrito, y proporcionan recomendaciones sobre aspectos específicos de redacción y edición. Dichas recomendaciones se basan en gran parte en la experiencia compartida por un cierto número de editores y autores, recogida a lo largo de muchos años, y no en los resultados de una investigación planificada y metódica que pretenda estar "basada en pruebas". Siempre que ha sido posible, las recomendaciones van acompañadas de las razones que las justifican; de ese modo el documento cumple también una finalidad educativa.

Los autores comprobarán que resulta útil seguir las recomendaciones de este documento, siempre que sea posible, porque seguirlas mejora la calidad y la claridad del texto de los manuscritos enviados a cualquier revista, y a la vez facilita el proceso de edición. Al mismo tiempo, las revistas tienen requisitos editoriales propios, que se ajustan a sus propósitos específicos. Por lo tanto, los autores deben familiarizarse con las instrucciones específicas de la revista elegida para publicar su manuscrito -por ejemplo, conviene que sepan qué temas son adecuados a una revista concreta y los tipos de artículos que se pueden presentar (por ejemplo, artículos originales, artículos de revisión o informes de casos clínicos)- y seguir dichas instrucciones.

\section{Consideraciones éticas en la realización y en la comunicación de una investigación}

\section{A. Autoría y contribuciones}

\section{A.1. Autores}

En general se considera que un "autor" es alguien que ha realizado contribuciones intelectuales sustantivas a un estudio publicado, y la autoría biomédica siempre ha tenido importantes implicaciones académicas, sociales y económicas. ${ }^{1}$ Un autor debe asumir la responsabilidad de que al menos una de las partes que componen la obra, debe poder identificar a los responsables de cada una de las demás partes, y sería deseable que confiara en la capacidad y en la integridad de aquellos con quienes comparte la autoría. En el pasado raramente se informaba a los lectores sobre el grado de contribución al estudio de los que aparecían en él como autores o en el apartado de agradecimientos. ${ }^{2}$ Actualmente algunas revistas solicitan y publican información sobre el grado de contribución de cada una de las personas que se citan como participantes en el estudio, al menos en el caso de una investigación original. Se solicita encarecidamente a los editores que desarrollen e

http://scielo.sld.cu 
implanten una política sobre las contribuciones, así como una política que permita identificar a la persona responsable de la integridad del trabajo en su conjunto.

Aunque, evidentemente, estas políticas sobre el grado de contribución y sobre la identificación del responsable eliminan gran parte de las ambigüedades respecto a las aportaciones, no resuelven la cuestión de la cantidad y la calidad de la aportación necesaria para que pueda ser calificada como autoría. El ICMJE recomienda los siguientes criterios para la autoría, criterios igualmente válidos para las revistas que distinguen entre autores y colaboradores.

- El reconocimiento de la autoría debería basarse en: 1) las aportaciones importantes a la idea y diseño del estudio, o a la recogida de datos, o al análisis e interpretación de datos; 2) la redacción del borrador del artículo o la revisión crítica de su contenido intelectual sustancial, y 3) la aprobación final de la versión que va a publicarse. Los autores deberían cumplir las condiciones 1, 2 y 3.

- Cuando el grupo que ha llevado a cabo el trabajo es numeroso y procede de varias instituciones, el grupo debería identificar a las personas que aceptan la responsabilidad directa del manuscrito. ${ }^{3}$ Estas personas deberían cumplir todos los criterios de autoría definidos más arriba y los editores deberían pedir a dichas personas que rellenen los formularios para autores y los de reconocimiento de conflicto de intereses. Cuando se presenta un manuscrito redactado por un grupo, el autor corresponsal debería indicar claramente la prelación en la mención de los autores e identificar inequívocamente a todos los autores individuales, así como el nombre del grupo. En general, las revistas citan al resto de miembros del grupo en los Agradecimientos. La NLM incluye en sus índices el nombre del grupo y los nombres de las personas que el grupo ha identificado como responsables directos del manuscrito; también hace una relación de los nombres de los colaboradores siempre que consten en los Agradecimientos.

- La búsqueda de financiación, la recogida de datos o la supervisión general del grupo de investigación no justifican por sí solos la autoría.

- Todas las personas consignadas como autores deben cumplir los criterios de autoría, y todas las que los cumplen deben aparecer en la lista de autores.

- La participación de los distintos autores en el trabajo debe ser suficiente como para aceptar públicamente la responsabilidad de la parte a su cargo del contenido.

Actualmente, algunas revistas también piden que uno o más autores, a los que se designa como "responsables", se identifiquen como las personas que asumen la responsabilidad de la integridad del trabajo como conjunto, desde su inicio hasta la publicación del artículo, y hacen pública esta información.

Cada vez más la autoría de los ensayos clínicos multicéntricos se atribuye a un grupo. Todos los miembros del grupo que se mencionan como autores deberían cumplir todos los criterios de autoría/colaboración.

El grupo debería decidir conjuntamente todo lo referente a los colaboradores/autores antes de enviar el manuscrito. El autor/garante responsable debería poder dar razón de la presencia y del orden en que aparece cada uno de los miembros. No es responsabilidad de los editores tomar decisiones acerca de la autoría/colaboración, ni intervenir como árbitro en conflictos de autoría. 


\section{A.2. Colaboradores que aparecen en los Agradecimientos}

Todos los colaboradores que no cumplen los criterios de autoría deberían aparecer en la sección de Agradecimientos. Ejemplos a incluir en los Agradecimientos: personas que colaboran sólo dando ayuda técnica, colaboraciones en la redacción del manuscrito, las direcciones de departamentos cuya participación sea de carácter general. Los editores deberían solicitar a los autores responsables que precisen si han disfrutado de colaboraciones en el diseño del estudio, recogida o análisis de datos, o preparación del manuscrito. En caso de que hayan dispuesto de este tipo de ayudas, los autores deberían hacer pública la identidad de las personas que les han prestado tales ayudas e identificar en el artículo objeto de publicación la entidad que las ha sufragado. Las ayudas económicas y materiales también deberían aparecer en los Agradecimientos.

Los grupos de personas que han contribuido materialmente al artículo pero cuya colaboración no justifica la autoría, deberían aparecer bajo un título tal como "investigadores clínicos" o "investigadores participantes", y asimismo debería describirse su función o contribución, como por ejemplo, "asesor científico", "ha realizado la revisión crítica de la propuesta del estudio", "ha recogido datos", o "ha proporcionado y cuidado de los pacientes del estudio".

Dado que los lectores pueden inferir que todas las personas que aparecen dan su aprobación a los datos y conclusiones, éstas deberán dar su autorización, por escrito, a aparecer en los Agradecimientos.

\section{B. Dirección}

\section{B.1. La función del editor (director)}

El editor (director) de la revista es la persona responsable de todo su contenido. Los propietarios y editores de las revistas médicas tienen un empeño común: la publicación de una revista legible y fiable, producida con la debida consideración a los objetivos definidos por la revista y a los costes. Sin embargo, las funciones de propietarios y editores son distintas. Los propietarios tienen derecho a nombrar y relevar a los editores y a tomar decisiones empresariales importantes en las que los editores deberían comprometerse y participar en la mayor medida posible. Los editores deben tener total autoridad para determinar el contenido editorial de la revista. Dicha noción de libertad editorial debería ser defendida con resolución por los editores, incluso hasta el punto de poner en juego sus puestos de trabajo. En la práctica, para garantizar esta libertad, el editor debería tener acceso directo a los más altos cargos de la empresa propietaria y no sólo al administrador delegado.

Además de las condiciones generales del contrato, los editores de las revistas médicas deberían disponer de unas cláusulas que establezcan claramente sus derechos y obligaciones, y que definan los mecanismos para resolver los casos de conflicto. Con el fin de establecer y mantener una política editorial puede ser útil disponer de un consejo editorial asesor independiente.

\section{B.2. Libertad editorial}

El ICMJE adopta la definición de libertad editorial de la Asociación Mundial de Editores Médicos (World Association of Medical Editors, http://www.wame.org/wamestmt.htm). Según dicha definición, la libertad o la independencia editorial supone que los editores jefe tienen plena autoridad sobre el contenido editorial de su revista y 
sobre la elección del momento de publicación. Los propietarios de la revista no deberían interferir en la evaluación, selección o edición de los artículos individuales, ni directamente ni creando un entorno que tuviera influencia considerable sobre las decisiones. Los propietarios de la revista no deberían exigir a los editores la publicación de suplementos como si ello formara parte de sus obligaciones contractuales. Los editores deberían basar sus decisiones en la validez del trabajo y en la importancia que puede tener para los lectores, en lugar de basarlas en el éxito comercial de la revista. Los editores deberían tener libertad para expresar puntos de vista críticos, aunque responsables, sobre todos los aspectos de la medicina sin miedo a represalias, aunque estos puntos de vista pudieran entrar en conflicto con los objetivos comerciales de la empresa editora.

Los editores y las organizaciones de editores tienen la obligación de secundar el concepto de libertad editorial y de comunicar las transgresiones más graves de dicha libertad a las comunidades internacionales médicas, académicas y también a otras comunidades no expertas.

\section{C. Evaluación por pares}

La evaluación imparcial, independiente y crítica es una parte intrínseca del proceso científico, y por lo tanto debe formar parte de todo trabajo académico. La evaluación por pares o por iguales (Peer review) es la valoración crítica de los manuscritos por parte de expertos que no forman parte del personal editorial. Por lo tanto, la evaluación por pares puede ser considerada una importante prolongación del proceso científico. Aunque su valor ha sido poco estudiado y se debate ampliamente, ${ }^{4}$ la evaluación por pares ayuda a los editores a decidir qué manuscritos son adecuados para sus revistas, a la vez que ayuda a autores y editores en sus esfuerzos para mejorar la calidad de los artículos. Una revista evaluada por pares es aquella que somete la mayoría de sus artículos de investigación a una evaluación externa. El número y tipo de manuscritos que se envían a evaluar, el número de revisores, los procedimientos de evaluación y la utilización que se haga de las opiniones de los revisores pueden variar según la revista. En aras de la transparencia, las revistas deberían hacer públicas sus políticas al respecto y los plazos normales de devolución del manuscrito en las instrucciones que facilitan a los autores.

\section{D. Conflictos de intereses}

La confianza pública en el proceso de evaluación por pares y la credibilidad de los artículos publicados depende en parte de cómo se tratan los conflictos de intereses durante la redacción, la evaluación por pares y la toma de decisiones editoriales. Existe conflicto de intereses cuando un autor (o la institución a la que pertenece el autor), evaluador o editor tienen relaciones (relaciones que también se conocen como compromisos duales, competencia de intereses o conflicto de lealtades) personales o financieras que influyen de forma poco adecuada (sesgo) en sus acciones. La importancia de estas relaciones varía. Unas son insignificantes y otras tienen enorme potencial para influir sobre los juicios. Además, no todas las relaciones suponen un verdadero conflicto de intereses. Y por otro lado la posibilidad de conflicto de intereses puede existir tanto si una persona cree que la relación afecta a su juicio científico como si no. Las relaciones financieras como empleo, asesorías, propiedad de acciones, honorarios, informes y peritajes -son los conflictos de intereses más fáciles de detectar y las que más probablemente socavarán la credibilidad de la revista, de los autores y de la propia ciencia. Sin 
embargo, pueden producirse conflictos por otras razones, como relaciones personales, rivalidad académica y pasión intelectual.

Todos los participantes en la evaluación por pares y en el proceso de publicación deben declarar todas las relaciones que podrían considerarse como potencial conflicto de intereses. La declaración de estas relaciones es también importante con respecto a los editoriales y a los artículos de revisión, porque puede ser más difícil detectar un sesgo en este tipo de publicaciones que en los artículos originales de investigación. Los editores deben usar la información de las declaraciones de conflicto de intereses y las declaraciones de intereses financieros como base para tomar sus decisiones editoriales. Los editores deberían publicar esta información si creen que es importante para la valoración del manuscrito.

II. D.1. Posibles conflictos de intereses relacionados con los compromisos de los autores

Cuando los autores presentan un manuscrito, tanto si se trata de un artículo como de una carta, son responsables de declarar todas las relaciones personales y financieras que pudieran sesgar su trabajo. Con el fin de evitar ambigüedades, los autores deben declarar explícitamente si existen o no posibles conflictos. Los autores deberían exponerlo en el manuscrito, en una página de notificación de conflictos de intereses, situada después de la portada, y dar detalles adicionales, si es necesario, en la carta de presentación del manuscrito (véase sección IV. A.3. Declaración de conflictos de intereses).

Los autores deberían identificar a las personas que han colaborado en la redacción del manuscrito y precisar la fuente de financiación de estas colaboraciones.

Los investigadores deben revelar los posibles conflictos al resto de participantes en el estudio y exponer en el manuscrito si así lo han hecho.

Asimismo, los editores deben decidir cuándo publicar la información sobre posibles conflictos revelada por los autores. En caso de duda, es mejor optar por su publicación.

II. D.2. Posibles conflictos de intereses relacionados con la financiación del proyecto

Cada vez más los estudios reciben fondos de empresas, de fundaciones privadas y del gobierno. Las condiciones a las que se sujeta esta financiación pueden influir en la investigación misma y desprestigiarla.

Los científicos tienen la obligación ética de publicar los resultados fiables y relevantes de su investigación.

Los investigadores no deberían establecer acuerdos que interfieran en su capacidad para acceder a los datos y para analizarlos independientemente o para redactar los manuscritos y publicarlos. Los autores deberían describir el papel del patrocinador del estudio, si es que lo hay, en el diseño del estudio, en la recogida, análisis e interpretación de datos, en la redacción del artículo y en la decisión de presentarlo para su publicación. Si la fuente de financiación no tuvo participación en estas tareas, los autores deberían hacerlo constar. Los sesgos que se puedan introducir cuando los patrocinadores están directamente implicados en la investigación son análogos a los otros tipos de sesgos metodológicos. Por ello, algunas revistas

http://scielo.sld.cu 
deciden incluir información sobre la implicación de los patrocinadores en la sección de métodos.

Los editores pueden pedir a los autores de un estudio financiado por un organismo con un interés patrimonial o financiero en los resultados, que firmen una declaración como "He tenido pleno acceso a todos los datos de este estudio y me hago totalmente responsable de la integridad de los datos y de la exactitud del análisis de los mismos". Debería fomentarse que los editores revisaran ejemplares del protocolo y/o de los contratos asociados con los estudios específicos del proyecto antes de aceptar para su publicación los artículos derivados de dichos estudios. Los editores pueden recabar un análisis estadístico de todos los datos realizado por un bioestadístico independiente. Los editores pueden rechazar un artículo si un patrocinador ha reclamado el control del derecho de los autores a publicar o no el artículo.

I. D.3. Posibles conflictos de intereses relacionados con los compromisos de los editores, del personal de la revista o de los revisores

Los editores deberían evitar seleccionar revisores externos que plantearan obvios conflictos de intereses, por ejemplo, aquellos que trabajen en el mismo departamento o institución que cualquiera de los autores. A menudo, los autores proporcionan a los editores los nombres de las personas a las que creen que no debería pedírseles que revisaran un manuscrito debido a posibles conflictos de intereses, normalmente de tipo profesional. Cuando sea posible, debería pedirse a los autores que explicaran o justificaran estas peticiones; dicha información es importante para los editores a la hora de decidir si las aceptan.

Los revisores deben revelar a los editores cualquier conflicto de intereses que pudiera afectar sus opiniones sobre el manuscrito, y deberían abstenerse de evaluar ciertos manuscritos en caso de que exista posibilidad de sesgo. Como en el caso de los autores, el silencio por parte de los revisores respecto a posibles conflictos puede significar o bien que estos conflictos existen pero no han sido detectados por el revisor, o bien que no hay conflictos. Por lo tanto, se pedirá a los revisores que expongan de forma explícita si existen o no estos conflictos. Los revisores no deben utilizar el conocimiento que tienen del trabajo, antes de su publicación, a favor de sus propios intereses.

Los editores que toman las decisiones finales sobre los manuscritos no deben tener ninguna implicación personal, profesional o financiera en ninguna de las cuestiones sometidas a su juicio. Si otros miembros del equipo editorial participan en la toma de decisiones, deben facilitar a los editores una declaración fehaciente de sus intereses financieros en la medida que podrían relacionarse con las opiniones editoriales -y abstenerse de tomar decisiones que puedan estar afectadas por un conflicto de intereses.

El personal del equipo editorial no debe usar con fines privados la información obtenida a través de su contacto con los manuscritos. Los editores deberían publicar declaraciones regulares sobre posibles conflictos de intereses relacionados con los compromisos del personal de la revista.

II. E. Privacidad y confidencialidad

II. E.1. Pacientes y participantes en el estudio 
Los pacientes tienen derecho a la privacidad, derecho que no debe ser violado sin el consentimiento informado. Todo lo que se refiere a la identificación, incluidos los nombres o iniciales de los pacientes o el número de historia clínica, no debería publicarse. Tampoco fotografías ni datos genealógicos, a menos que dicha información sea esencial para los objetivos científicos y que el paciente o su progenitor o tutordé el consentimiento escrito para su publicación. El consentimiento informado para este propósito requiere enseñar el manuscrito que va a publicarse al paciente que pueda ser objeto de identificación.

Los autores deberían comunicar a estos pacientes si alguno de estos materiales potencialmente identificables va a ser accesible vía Internet o en forma de libro tras su publicación. El consentimiento del paciente debería hacerse por escrito y acordarse con la revista, con los autores, o con ambos, de acuerdo con lo que determinen las leyes o la normativa específica. La normativa legal varía según los lugares, y las revistas deberían fijar su política con asesoramiento legal. Dado que la revista que guarda el consentimiento puede conocer la identidad del paciente, puede que algunas revistas decidan que la confidencialidad del paciente se garantiza mejor si es el autor quien archiva el consentimiento, y éste a su vez certifica por escrito a la revista que ha obtenido y tiene en su poder una copia escrita del consentimiento del paciente.

Los detalles de identificación deberán omitirse si no son esenciales. Sin embargo, en caso de que exista alguna duda sobre la posibilidad de mantenimiento del anonimato, debe conseguirse un consentimiento informado. Por ejemplo, ocultar la región ocular en las fotografías de los pacientes no es una protección adecuada para preservar el anonimato. Si para proteger el anonimato se alteran las características identificativas, como en los pedigríes genéticos, los autores deberán asegurarse de que dichas alteraciones no van a distorsionar el significado científico y los editores deberán hacerlo constar. La exigencia del consentimiento informado debería incluirse en las instrucciones para autores. En los casos en que se haya obtenido dicho consentimiento, debería indicarse en el artículo.

\section{E.2. Autores y revisores}

Los manuscritos deben evaluarse con el debido respeto a la confidencialidad de los autores. Al someter los manuscritos a evaluación, los autores confían a los editores los resultados de su trabajo científico y de su esfuerzo creativo, de los que puede depender su reputación y su carrera. Los derechos de los autores pueden ser violados si se revelan detalles confidenciales durante la revisión de su manuscrito. Los revisores o evaluadores también tienen derechos de confidencialidad, que deben ser respetados por el editor. La confidencialidad puede no respetarse en caso de falsedad o fraude, pero de lo contrario debe ser mantenida.

Los editores no deben revelar información alguna sobre los manuscritos incluidos el momento de recepción, el contenido, el estado del proceso de evaluación, la crítica por parte de los revisores o el destino último- a ninguna persona aparte de los autores y revisores. Esto incluye los requerimientos para el uso de los materiales para procedimientos legales.

Los editores deben aclarar a sus revisores que los manuscritos que les envían para evaluar son escritos confidenciales y que son propiedad privada de los autores. Por lo tanto, los revisores y el personal de la editorial deben respetar los derechos de los autores y no comentar públicamente el trabajo de los autores ni apropiarse de sus ideas antes de que el manuscrito se publique. Los revisores no están autorizados a realizar copias del manuscrito para sus archivos y tienen prohibido

http://scielo.sld.cu 
compartirlo con otras personas, excepto si cuentan con la autorización del editor. Los revisores deberían devolver o destruir las copias de los manuscritos una vez evaluados. Los editores no deberían guardar copias de los manuscritos rechazados.

Los comentarios del revisor no deben publicarse ni hacerse públicos sin el permiso del revisor, del autor y del editor.

Existen distintas opiniones sobre si los revisores deben permanecer en el anonimato. Los autores deberían consultar la Información a los Autores de la revista a la que han decidido enviar su manuscrito para saber si las revisiones son anónimas. Cuando los comentarios no están firmados, la identidad de los revisores no debe revelarse al autor ni a ninguna otra persona sin la autorización del propio revisor.

Algunas revistas publican los comentarios de los revisores junto con el manuscrito. Dicho procedimiento no debería adoptarse sin el consentimiento de los autores y revisores. Sin embargo, los comentarios de los revisores pueden enviarse a otros revisores del mismo manuscrito -lo cual ayuda a los revisores a conocer el estado del proceso de evaluación- y la decisión del editor sobre si ha decidido aceptar o rechazar un manuscrito puede notificarse a los revisores.

II. F. Protección de las personas y de los animales que participan en la investigación

Cuando se informa de experimentos con seres humanos, los autores deberían indicar si los procedimientos seguidos cumplen los principios éticos de la comisión responsable de la experimentación humana (institucional y nacional) y de la Declaración de Helsinki de 1975 , revisada en el año $2008 .^{5}$ Si existe alguna duda sobre si la investigación se llevó a cabo cumpliendo la Declaración de Helsinki, los autores deben explicar las razones de su metodología y demostrar que el comité de ética de su institución aprobó los aspectos dudosos del estudio. En el caso de realizar experimentos con animales, los autores deberían indicar si se han cumplido las normativas nacionales e institucionales para el cuidado y uso de animales de laboratorio.

\section{Aspectos sobre edición y publicación en revistas biomédicas}

III. A. Obligación de publicar los estudios con resultados negativos

Los editores deberían considerar seriamente la publicación de cualquier estudio realizado correctamente sobre una cuestión importante y pertinente para sus lectores, si los resultados son estadísticamente significativos ya sea en un objetivo primario ya sea en uno secundario. La decisión de no presentar o publicar hallazgos por falta de significación estadística es una importante causa de sesgo de publicación.

\section{B. Correcciones, Retractaciones y Notas de reserva}

Los editores deben asumir en principio que el trabajo que presentan los autores está basado en observaciones honestas. Sin embargo, es posible que surjan dos tipos de problemas.

En primer lugar, en los artículos publicados pueden encontrarse errores que requieran una corrección o fe de erratas de una parte del trabajo. Las correcciones

http://scielo.sld.cu 
deberían aparecer en una página numerada, formar parte del índice, incluir la citación original completa y estar vinculadas al artículo original (y viceversa si se trata de una publicación online). Aunque es improbable, cabe la posibilidad de que un error sea tan grave que pueda desmerecer el grueso del trabajo; si esto ocurre, autores y editores deben otorgar un tratamiento específico caso por caso. Un error de esa índole no debería confundirse con las deficiencias que quedan al descubierto por la aparición de nuevas informaciones científicas en el curso normal de la investigación. Esto último no requiere correcciones ni tampoco retractaciones.

El segundo problema es el fraude científico. Si surgen dudas razonables sobre la honestidad o integridad del trabajo, tanto si ha sido enviado para su publicación como si ya ha sido publicado, es responsabilidad del editor garantizar que la cuestión tiene un seguimiento adecuado, generalmente por parte de la institución que patrocina al autor. Sin embargo, no acostumbra a ser tarea del editor llevar a cabo una investigación completa o tomar una determinación; dicha responsabilidad corresponde a la institución donde se ha llevado a cabo el trabajo o al organismo que proporciona los fondos. El editor debería ser inmediatamente informado de la decisión final y, en caso de haberse publicado ya un artículo fraudulento, la revista debe publicar una retractación. Si la investigación no conduce a una conclusión satisfactoria, el editor puede decidir llevar a cabo su propia investigación. Como alternativa a la retractación, el editor puede decidir publicar una Nota de reserva (Expressions of Concern) en la que exprese sus dudas acerca de la validez del trabajo publicado.

La retractación o la nota deberían aparecer en una página numerada y en una sección destacada de la revista impresa así como de la versión electrónica, formar parte del índice e incluir en el encabezamiento el título del artículo original. No debería limitarse a una carta al director. Lo ideal seria que el primer autor fuera el mismo en la retractación que en el artículo, aunque en determinadas circunstancias el director puede aceptar retractaciones de otras personas responsables del trabajo. El texto de la retractación debería explicar los motivos de ésta e incluir la cita completa del original al que se alude.

No puede asumirse que los trabajos anteriores del autor de un artículo fraudulento tengan validez. Los editores pueden pedir al organismo al que pertenece el autor que les garantice la validez de los trabajos previos publicados en sus revistas o bien que se retracten de los mismos. En caso de no hacerse, los editores pueden decidir publicar una nota donde expresen sus dudas sobre la validez de los trabajos previamente publicados. Los editores que tengan dudas sobre el recto comportamiento editorial o científico les será de utilidad consultar los excelentes diagramas que ha desarrollado el Committee on Publication Ethics (COPE) (http://www.publicationethics.org.uk). El COPE, que se fundó en 1997, es un foro en el cual los editores de revistas con revisión por pares pueden discutir aspectos relacionados con la honestidad de la producción científica. Además apoya y anima a los editores a identificar, catalogar y desarrollar estudios sobre los problemas éticos típicos del proceso de publicación. El principal objetivo del COPE consiste en proporcionar a los editores una caja de resonancia con la que poder afrontar mejor los posibles conflictos éticos en investigación y en publicación.

\section{C. Derechos de autor}

Muchas revistas biomédicas piden a los autores que cedan los derechos de autor (copyright) a la revista. Sin embargo, un número cada vez mayor de revistas de "acceso libre" no requiere transferencia de los derechos de autor. Los editores deberían dejar clara a los autores y a otras personas interesadas en usar el 
contenido editorial de sus revistas su posición con respecto a la cesión del derecho de autor.

El estatus del derecho de autor de los artículos de una revista determinada puede variar: algunos contenidos pueden no estar protegidos por el derecho de autor (por ejemplo, los artículos redactados por funcionarios de los EE. UU. y de otros gobiernos durante el ejercicio de su cargo); los editores pueden acordar renunciar al derecho de autor de algunos artículos; otros, en fin, pueden estar protegidos por derechos de series (es decir, se permite el uso en publicaciones que no sean revistas, incluidas las electrónicas).

III. D. Publicaciones solapadas

\section{D.1. Envíos duplicados}

La mayoría de revistas biomédicas no toman en consideración los manuscritos que simultáneamente se han enviado a otras revistas. Entre las principales consideraciones que han conducido a esta política se incluyen: 1) las posibilidades de desacuerdo cuando dos o más revistas exigen el derecho a publicar un manuscrito que ha sido enviado simultáneamente a más de una; y 2) la posibilidad de que dos o más revistas emprendan, innecesariamente y sin saberlo, el trabajo de evaluación y revisión del mismo manuscrito y publiquen el mismo artículo.

Sin embargo, los editores de distintas revistas pueden decidir publicar simultáneamente o conjuntamente un artículo si creen que hacerlo redundará en interés de la salud pública.

\section{D.2. Publicación redundante}

Una publicación redundante (o duplicada) es la publicación de un artículo que se solapa o coincide sustancialmente con uno ya publicado en versión impresa o electrónica.

Los lectores de fuentes primarias, tanto impresas como electrónicas, deben poder confiar en que aquello que leen es original, a menos que de forma clara se especifique que el artículo se vuelve a publicar por decisión consciente del autor y del editor. Esta decisión se basa en las leyes internacionales sobre el copyright, en una conducta ética y en el uso eficaz de los recursos. Una publicación duplicada de una investigación original es particularmente problemática dado que puede dar lugar a que se compute inadvertidamente un artículo dos veces o a una ponderación inadecuada de los resultados de un estudio, lo que distorsiona la acumulación de las pruebas disponibles sobre el tema.

La mayoría de revistas no desean recibir artículos sobre trabajos una parte de los cuales haya sido expuesta en artículos ya publicados o que esté contenida en otro artículo enviado o aceptado para su publicación en versión impresa o electrónica. Esta política no excluye que la revista decida publicar un artículo que ha sido rechazado por otra revista, o un artículo completo posterior a la publicación de uno preliminar, como puede ser un resumen o un póster presentado en un congreso. Tampoco es descartable que las revistas se planteen publicar un trabajo que se ha presentado en una reunión científica pero que no se ha publicado por completo o cuya publicación está prevista en actas o en un formato similar. En general, los breves comunicados de prensa de las reuniones científicas no se consideran infracciones de esta regla, aunque podrían serlo si en estos comunicados se

http://scielo.sld.cu 
proporcionara algún dato adicional o mediante tablas o ilustraciones se diera mayor amplitud al comunicado.

EI ICMJE no considera como publicaciones previas las inscripciones en el registro de los resultados de ensayos clínicos siempre que dichos resultados sean presentados en el mismo registro en el que se registró la metodología del ensayo, y siempre que los resultados se inscriban en la forma de un breve resumen estructurado o de tabla. El ICMJE cree también que el registro de resultados o bien debería remitir a la publicación completa de los resultados, cuando esté disponible, o bien incluir una nota indicando que los resultados aún no se han publicado en una revista con revisión.

Al enviar un artículo, el autor siempre debe hacer una declaración al editor de todos los trabajos enviados para publicar y de artículos previos (incluyendo presentaciones en congresos e inscripciones de resultados en el registro) que pudieran ser considerados publicaciones redundantes o duplicados del mismo trabajo o similar. El autor debe avisar al editor en caso de que el manuscrito incluya temas sobre los que los autores han publicado un artículo previo o han presentado un manuscrito relacionado con él en otra revista. Cualquier trabajo de este tipo debe ser citado y referenciado en el nuevo artículo. Las copias de este material deberán incluirse con el manuscrito que se presenta para ayudar al editor a decidir cómo abordar la cuestión.

Si se intenta o tiene lugar una publicación redundante o duplicada sin mediar notificación alguna, los autores deberán contar con que el editor va a tomar medidas al respecto. Como mínimo, deberá suponerse que el manuscrito presentado va a rechazarse de inmediato. En caso de que el editor no fuera consciente de dichas violaciones y el artículo ya se hubiera publicado, probablemente se publicará una nota que informe de la publicación redundante o duplicada con o sin la explicación o aprobación del autor.

Dar a conocer con antelación a los medios de comunicación, organismos gubernamentales o fabricantes la información científica expuesta en un artículo o carta al editor que ya ha sido aceptada pero todavía no se ha publicado vulnera la política de muchas revistas. Esta información previa puede justificarse si el artículo o carta describen importantes avances terapéuticos o riesgos para la salud pública, como los efectos adversos de medicamentos, vacunas u otros productos biológicos, dispositivos médicos o enfermedades de declaración obligatoria. Esta información previa no debe hipotecar o suponer un perjuicio para la publicación, sino que debe comentarse previamente con el editor y llegar a un acuerdo.

\section{D.3. Publicación secundaria aceptable}

Determinados tipos de informaciones, tales como las directrices de organismos gubernamentales y organizaciones profesionales, puede ser deseable que lleguen a un público lo más amplio posible. En estos casos, a veces los editores deciden deliberadamente publicar material que también está siendo publicado en otras revistas, con el acuerdo de los autores y editores de dichas revistas. La publicación secundaria por otros motivos, en el mismo o en otro idioma y especialmente en otros países, es justificable, y puede ser beneficiosa, cuando se cumplan en su totalidad las condiciones siguientes:

1. Los autores han recibido la aprobación de los editores de ambas revistas (el editor interesado en la publicación secundaria debe tener una fotocopia, una separata o un manuscrito de la versión original).

http://scielo.sld.cu 
2. La prioridad de la publicación primaria es respetada si transcurre un intervalo de tiempo entre ambas publicaciones de una semana como mínimo (a no ser que se negocie de otro modo por parte de los editores de ambas publicaciones).

3. El artículo de la publicación secundaria se dirige a un grupo diferente de lectores, con lo que una versión abreviada podría ser suficiente.

4. La versión secundaria refleja fielmente los datos e interpretaciones de la versión primaria.

5. Una nota a pie de página, en la página que contiene el título de la versión secundaria, informa a los lectores, revisores y grupos de documentación de que el artículo ha sido publicado por completo o en parte, y da la referencia original. Una nota a pie de página adecuada podría ser: "Este artículo está basado en un estudio presentado previamente en [título de la revista con la referencia completa]."

La autorización para una publicación secundaria de estas características debería ser gratuita.

6. En el título de dicha publicación debería indicarse que se trata de una publicación secundaria (reedición completa, reedición abreviada, traducción completa o traducción abreviada) de una publicación primaria. Téngase en cuenta que la NLM no considera que las traducciones sean "reediciones" y no cita ni indexa las traducciones si el artículo original ha sido publicado en una revista indexada en MEDLINE.

7. Los editores de revistas que publican simultáneamente en varias lenguas deben tener presente que la NLM indexa la versión en la primera lengua. Cuando el texto completo de un artículo aparece en más de una lengua en el mismo número de una revista (como es el caso de revistas canadienses con el mismo artículo en francés y en inglés), se hace indicación de ambas lenguas en la cita MEDLINE (por ejemplo, Mercer K. The relentless challenge in health care. Health Manage Forum. 2008 summer; 21(2):4-5. English, French. No abstract available. PMID: 18795553).

\section{D.4. Manuscritos concurrentes basados en el mismo estudio}

La publicación de manuscritos para evidenciar desavenencias entre los investigadores que han participado en un mismo trabajo puede malgastar espacio en la revista y confundir a los lectores. Por otra parte, si los editores publican a sabiendas un manuscrito redactado solamente por una parte de los colaboradores de un estudio, podrían estar negando al resto del equipo su derecho legítimo de coautoría y también podrían estar negando a los lectores de la revista el acceso a las legítimas diferencias de opinión sobre la interpretación de los resultados del estudio.

Se consideran dos tipos de manuscritos concurrentes (competing manuscripts): los enviados por colaboradores que disienten sobre el análisis y la interpretación de los resultados del estudio, y los enviados por colaboradores que disienten sobre los resultados y sobre los datos que deberían darse a conocer.

Dejando aparte la cuestión no resuelta de la autoría de datos, las siguientes observaciones generales pueden ayudar a los editores y a otras personas a afrontar dichos problemas. 


\section{D.4.a. Discrepancias en el análisis o en la interpretación}

Si la discusión se centra en el análisis o en la interpretación de datos, los autores deberían enviar un manuscrito que presentara claramente las diferentes interpretaciones. La diferencia de opiniones debería explicarse en la carta de presentación. El proceso normal de evaluación y revisión editorial del manuscrito puede ayudar a los autores a resolver sus discrepancias sobre el análisis y la interpretación.

Si no puede llegarse a un acuerdo y el estudio tiene interés, deberían publicarse ambas versiones, ya sea publicando dos artículos sobre el mismo estudio o bien un solo artículo con los dos análisis o interpretaciones. En estos casos, sería apropiado que el editor publicara una nota explicando resumidamente las discrepancias y la voluntad de la revista de intentar resolverlas.

\section{D.4.b. Discrepancias en los métodos o resultados}

Si la discusión se centra en opiniones que disienten sobre lo que se hizo o se observó realmente a lo largo del estudio, el editor de la revista debería rechazar la publicación hasta que se resuelva el desacuerdo. No es previsible que la evaluación por pares vaya a resolver este tipo de problemas. Si hay acusaciones de deshonestidad o fraude, los editores deben informar a las autoridades correspondientes; los autores deberían ser advertidos de la intención del editor de notificar una sospecha de mala conducta investigadora.

\section{D.5. Manuscritos concurrentes basados en la misma base de datos}

A veces los editores reciben manuscritos de grupos de investigación independientes que han analizado un mismo conjunto de datos (por ejemplo, una base de datos pública). Los manuscritos pueden diferir en los métodos de análisis, en las conclusiones o en ambas cosas. Los manuscritos deberían considerarse por separado. Si las interpretaciones de unos mismos datos son muy similares es razonable, pero no necesario, que los editores den preferencia al primer manuscrito recibido. Sin embargo, en estas circunstancias es razonable que la editorial revise los diversos manuscritos, e incluso puede que haya una buena razón para publicar más de uno, dado que los distintos enfoques pueden ser complementarios e igualmente válidos.

\section{E. Cartas de los lectores}

El autor/garante responsable tiene la responsabilidad principal respecto a la correspondencia con la revista, pero el ICMJE recomienda que los editores envíen una copia de toda la correspondencia a cada uno de los que figuran como autores.

Las revistas biomédicas deberían facilitar al público lector un mecanismo para someter sus comentarios, preguntas o críticas sobre los artículos publicados, así como para originales breves y comentarios no relacionados con los artículos ya publicados. Probablemente, aunque no necesariamente, este mecanismo adoptará la forma de una sección de cartas. Debería darse a los autores de los artículos comentados en las cartas la oportunidad de responder, preferiblemente en el mismo número en que aparece la carta. Se pedirá a los autores de las cartas que declaren cualquier concurrencia o conflicto de intereses.

http://scielo.sld.cu 
Las cartas publicadas pueden ser retocadas para respetar la extensión, la corrección gramatical y el estilo de la revista. Asimismo, los editores pueden decidir publicar cartas sin modificar su extensión o estilo, como por ejemplo en la sección de respuesta rápida de la revista en Internet; la revista debería manifestar su práctica editorial a este respecto. Los autores deberían dar su aprobación a los cambios editoriales que alteren el contenido o el tono de una carta o de una respuesta. En todo caso, los editores deben hacer el esfuerzo de evitar afirmaciones desconsideradas, inexactas o calumniosas, y no deben permitir que se lancen ataques personales con la finalidad de desacreditar opiniones o resultados.

Aunque los editores tengan la prerrogativa de rechazar la correspondencia que no consideren importante, interesante o que carezca de argumentos convincentes, tienen la responsabilidad de permitir que se exprese todo un espectro de opiniones. La sección de Cartas de los lectores no debe usarse para promocionar los puntos de vista de la revista o de los editores.

En interés de la imparcialidad y de que la sección de Cartas tenga unas proporciones razonables, puede que las revistas establezcan límites a las respuestas al material publicado, y también a los debates sobre un tema determinado. Las revistas también deberían decidir si informan a los autores cuando va a aparecer, en una sección estándar o en una de respuestas rápidas, una carta sobre su trabajo publicado.

Las revistas también deben establecer una política respecto al almacenamiento o archivo de cartas sin editar publicadas en formato electrónico (en línea). Estas políticas deben hacerse públicas tanto en la versión sobre papel como en la versión electrónica de la revista.

\section{F. Suplementos, números monográficos y series especiales}

Los suplementos son compilaciones de artículos que tratan sobre un tema o cuestiones relacionadas, se publican en un número independiente de la revista o como una parte de un número habitual, y normalmente están financiados por fuentes distintas a las de la editorial que publica la revista. Está comprobado que el contenido de un suplemento puede ser de una calidad inferior a la de la revista matriz. Dado que las fuentes de financiación pueden sesgar el contenido de los suplementos a través de la elección de temas y opiniones, las revistas deben plantearse adoptar los siguientes principios. Estos mismos principios se aplicarán a los números monográficos y a las series especiales que tienen financiación externa y/o editores invitados.

1. El editor debe recibir y asumir la total responsabilidad de las políticas, prácticas y contenido de los suplementos, incluido el control total de la decisión de escoger autores, revisores y contenido del suplemento. No debe permitirse que la entidad financiadora intervenga en el proceso de edición.

2. El editor de la revista debe tener la autoridad exclusiva para enviar los manuscritos del suplemento para que sean evaluados por personas externas y para rechazarlos. Estas condiciones deben darse a conocer a los autores y editores externos del suplemento antes que empiece el trabajo editorial del suplemento.

3. El editor de la revista debe aprobar el nombramiento de cualquier editor externo del suplemento y asumir la responsabilidad del trabajo del editor externo.

4. La procedencia de la idea del suplemento, las fuentes de financiación de la investigación, de la publicación, y los productos fabricados por el financiador que intervienen en el suplemento deben ser claramente especificados y visibles en un 
lugar destacado del suplemento, preferiblemente en todas las páginas. Siempre que sea posible, la financiación de los suplementos debe proceder de más de un patrocinador.

5. La publicidad en los suplementos debe seguir la misma política que la del resto de la revista.

6. Los editores de la revista deben procurar que los lectores distingan las páginas ordinarias de las páginas del suplemento.

7. Los editores de la revista y los editores del suplemento no deben aceptar favores ni remuneraciones personales de los patrocinadores del suplemento.

8. La publicación secundaria en los suplementos (volver a publicar artículos previamente publicados en otra parte) debería estar claramente identificada citando el artículo original. Los suplementos deberían evitar publicaciones redundantes o duplicadas. Los suplementos no deberían publicar de nuevo los resultados de una investigación anterior, aunque podría ser adecuado volver a publicar directrices u otro material de interés público.

9. Los principios de autoría y sobre posibles conflictos de intereses, tratados en otra parte de este documento, deberían también aplicarse a los suplementos.

\section{III.G. Publicación electrónica}

Actualmente la mayoría de las revistas biomédicas se publican en versión impresa y en versión electrónica, y algunas se publican solamente en versión electrónica. Dado que la publicación electrónica (que incluye Internet) es lo mismo que la publicación impresa, en beneficio de la claridad y la coherencia, las recomendaciones de este documento también deberían aplicarse a la información médica y sanitaria publicada en formato electrónico.

La naturaleza de la publicación electrónica requiere algunas consideraciones especiales, que competen a este documento aunque exceden sus propósitos. Como mínimo, los sitios web deben indicar: nombres, credenciales, afiliaciones y conflictos de intereses de editores, autores y colaboradores; documentación, referencias y fuentes de todos los contenidos; información sobre el copyright; información de la propiedad del sitio web; e identificación del patrocinador, de la publicidad y de la financiación.

Los enlaces entre un sitio de Internet sanitario o médico y otro pueden interpretarse como una recomendación implícita de calidad del segundo sitio. Por ello, las revistas deben actuar con cautela antes de realizar enlaces con otras páginas web; puede ser útil que aparezca un mensaje cuando se abandona la página web de la revista. Si los enlaces a otras páginas se ponen por razones económicas, debería indicarse claramente. Asimismo, deberían indicarse las fechas en que se cuelga un contenido por primera vez y las fechas de actualización. Tanto en la presentación electrónica como en la impresa, los mensajes publicitarios y promocionales no deben yuxtaponerse con el contenido editorial, y el contenido comercial debe ser identificado claramente como tal.

La publicación electrónica está en continuo estado de cambio. Los editores deben desarrollar e implantar políticas sobre aspectos específicos de las publicaciones electrónicas, y facilitarlas a los autores. Dichos aspectos incluyen el archivo, la corrección de errores, el control de las versiones, la elección entre el formato impreso o electrónico como revista de referencia, y la publicación de material auxiliar.

http://scielo.sld.cu 
En ningún caso una revista debe retirar un artículo de su página web o de su archivo. Si un artículo necesita alguna corrección o retractación, la aclaración debe señalarse adecuadamente y comunicarse tan pronto como sea posible en una página citable del siguiente número de la revista.

La conservación de artículos electrónicos en un archivo permanente es esencial para la documentación histórica. El acceso al archivo debe ser inmediato y controlado por un tercero, por ejemplo, una biblioteca mejor que una editorial. Mucho mejor aun es el depósito en archivos de diferentes lugares.

\section{H. Publicidad}

La mayoría de revistas médicas contienen publicidad que genera ingresos a la editorial, pero no debe permitirse que la publicidad influya en las decisiones editoriales. Las revistas deben tener políticas escritas, formales y explícitas para la publicidad, tanto en la versión impresa como en la electrónica; la política publicitaria en el sitio web debe coincidir con la política para la versión impresa. Los editores deben tener la autoridad última y plena para aprobar la publicidad y aplicar la política publicitaria.

Allí donde existan organismos independientes para evaluar la publicidad, los editores deberían hacer uso de sus criterios. Los lectores deben poder distinguir de inmediato entre el material publicitario y el editorial. Debe evitarse la yuxtaposición de material editorial y publicitario sobre los mismos productos o temas. Las páginas publicitarias que aparecen intercaladas en los artículos entorpecen la lectura, ya que interrumpen el flujo del contenido, y deben evitarse. No se debe contratar publicidad basándose en la premisa de que va a aparecer en el mismo número que un artículo determinado.

Las revistas no deberían estar dominadas por la publicidad, pero además los editores deberían ser precavidos en cuanto a publicar anuncios de sólo uno o dos anunciantes, ya que puede que los lectores perciban que dichos anunciantes han influido al editor.

Las revistas no deberían anunciar productos manifiestamente perjudiciales para la salud, por ejemplo el tabaco. Los editores deberían garantizar que respetan los reglamentos y las normas de comportamiento para la publicidad de su país, o bien elaborar sus propios principios. Los intereses de las organizaciones u organismos no deben controlar los anuncios por palabras u otros anuncios no gráficos, excepto cuando la ley así lo requiera. Finalmente, los editores deben considerar la posibilidad de publicar todas las críticas que reciban sobre los anuncios publicados en la revista.

\section{I. Revistas médicas y medios de comunicación}

El interés del público por las noticias sobre las investigaciones médicas ha llevado a los medios de comunicación a una fuerte competición para obtener dicha información. A veces, los investigadores e instituciones promocionan los resultados de una investigación en medios de comunicación, a través de ruedas de prensa o entrevistas, antes de publicarlos en una revista científica.

El público tiene derecho a acceder a la información médica importante en unos plazos de tiempo razonables, y los editores son responsables de facilitar este proceso. Las revistas biomédicas se publican básicamente para sus lectores, pero el 
público en general tiene un interés legítimo en su contenido; por lo tanto, encontrar el equilibrio adecuado entre estos intereses complementarios es lo que debe guiar la interacción de la revista con los medios de comunicación. Los médicos necesitan disponer de los informes detallados para aconsejar a sus pacientes sobre las conclusiones de los trabajos. Pero, además, la divulgación en los medios de comunicación de artículos sobre investigaciones científicas, antes de que el trabajo haya sido evaluado y publicado por completo puede llevar a difundir conclusiones inexactas o prematuras.

En algunos países se ha establecido un sistema de embargo o restricción para evitar la publicación de reportajes en los medios de comunicación antes de que aparezca en la revista el artículo original. Esta restricción crea una situación de equilibrio que la mayoría de periodistas agradecen, dado que minimiza la presión que tienen que soportar para publicar reportajes que no han podido preparar cuidadosamente. Una adecuada elección del momento para publicar estos reportajes también es importante para minimizar posibles efectos de caos económico, ya que algunos artículos contienen información con una gran potencialidad para influir en los mercados financieros. Pero el sistema de embargo ha sido también cuestionado con el argumento de que sirve a los intereses de la propia revista e impide la rápida difusión de la información científica.

Las siguientes recomendaciones pueden ser de utilidad a los editores, ya que su objetivo es establecer políticas sobre dichas cuestiones.

- Los editores, de hecho, pueden canalizar (a través de revistas con evaluación por pares) la transmisión regular de la información médica desde los investigadores hasta el público. Esto puede llevarse a cabo mediante un acuerdo con los autores que determine que no darán a conocer su trabajo mientras los manuscritos estén siendo estudiados o pendientes de publicación, y un acuerdo con los medios de comunicación por el cual éstos no publicarán reportajes antes de que se publiquen en las revistas los artículos originales; a cambio, la revista colaborará con los medios para que preparen unos buenos reportajes.

- Los editores deben tener presente que un sistema de embargo se basa en la confianza mutua; no existen mecanismos de control ni legales que aseguren su cumplimiento. La decisión por parte de un número importante de los medios de comunicación o de revistas biomédicas de no respetar el sistema de embargo implicaría su rápida disolución.

- Muy pocas investigaciones médicas tienen implicaciones clínicas tan importantes, claras y urgentes para la salud pública que deban darse a conocer antes de su publicación completa en una revista. Sin embargo, en tales circunstancias excepcionales, las autoridades competentes responsables de la salud pública deben decidir sobre la conveniencia de difundir con antelación la información a los profesionales y a los medios de comunicación, y hacerse responsables de su decisión. Si el autor y las autoridades competentes desean disponer libremente del manuscrito que una determinada revista está estudiando, deberían consultar al editor antes de su difusión pública. Si los editores aceptan la necesidad de dar a conocer el artículo inmediatamente, deberán renunciar en este caso al sistema de embargo.

- Las políticas diseñadas para limitar la publicidad previa a la publicación no deberían aplicarse a los reportajes de los medios sobre comunicaciones presentadas a reuniones científicas, ni a los resúmenes de dichas reuniones (véase sección III.D.2. Publicación redundante). Los investigadores que presentan su trabajo en una reunión científica deberían tener libertad para debatir sus comunicaciones con los periodistas, pero deberían abstenerse de ofrecer mayor 
cantidad de detalles sobre el estudio de los que presentaron en su ponencia o comunicación.

- Cuando un artículo está a punto de ser publicado, los editores deberían ayudar a los medios de comunicación a preparar notas de prensa con informaciones precisas, respondiendo a sus preguntas, proporcionándoles ejemplares del número de la revista o remitiéndolos a los expertos apropiados. Esta ayuda debería compensarse con la colaboración de los medios de comunicación para dar a conocer los reportajes coincidiendo con la publicación del artículo.

- Editores, autores y medios de comunicación deberían aplicar los principios descritos más arriba al material publicado tempranamente en las versiones electrónicas de las revistas.

\section{J. Registro obligatorio de los ensayos clínicos}

EI ICMJE considera que es importante promover una base de datos de ensayos clínicos que sea lo más exhaustiva posible y asequible al público. Un ensayo clínico es, según la definición del ICMJE, cualquier proyecto de investigación que prospectivamente asigna seres humanos a grupos de intervención, o de comparación concurrente o de control para estudiar la relación causa-efecto entre una intervención médica y un resultado de salud. Se entiende por intervención médica el uso de medicamentos, procedimientos quirúrgicos, dispositivos, tratamientos conductuales, cambios en el proceso de cuidados, entre otros.

Las revistas asociadas al ICMJE exigirán la inscripción en un registro público de ensayos como condición para la toma en consideración de la publicación en sus revistas. Los detalles de esta política se explican en una serie de editoriales (véase Editoriales, en el enlace Preguntas Más Frecuentes de la página Web del ICMJE http://www.icmje.org/faq clinical.html). El ICMJE alienta a los editores de las demás revistas biomédicas a que adopten una política similar.

EI ICMJE no recomienda ningún registro en particular, pero sus revistas asociadas exigirán a sus autores que inscriban sus ensayos en un registro que cumpla varios criterios. El registro deberá ser asequible al público gratuitamente. Debe estar abierto a todos los futuros usuarios que deseen registrar ensayos y debe ser gestionado por una organización sin ánimo de lucro. Debe existir un mecanismo que asegure la validez de los datos del registro y el registro debe admitir búsqueda electrónica. El registro de ensayos con campos vacíos o campos que contengan terminología banal no es adecuado.

Es importante destacar que el ICMJE exige el registro de la metodología del ensayo pero no el de sus resultados. Reconoce los problemas que podrían derivarse de la exposición de los resultados de una investigación que no hayan sido objeto de un proceso independiente de revisión. EI ICMJE entiende, en cambio, que la U.S. Food and Drug Administration Amendments Act de 2007 (FDAAA) exige a los investigadores el registro de los resultados. El ICMJE no considerará que los resultados sean una publicación previa si están incluidos en el mismo registro primario del ensayo clínico inicial y si los resultados se exponen en el formato de tabla que indica la FDAAA. Los investigadores deben saber que los editores de revistas que siguen las recomendaciones de la ICMJE pueden considerar publicación previa cualquier descripción de resultados clínicos más detallada, así como la publicación de resultados en registros diferentes del primario (en el caso de FDAAA, http://clinicaltrials.gov). El ICMJE prevé que la opinión acerca del registro de resultados cambiará radicalmente en los próximos años y el ICMJE puede verse 
obligado a modificar estas recomendaciones a medida que los respectivos organismos generen normativa diferente respecto al registro de resultados.

EI ICMJE recomienda que las revistas publiquen el número de registro del ensayo al final del resumen.

EI ICMJE recomienda también que cuando se disponga de número de registro los autores mencionen este número la primera vez que usen la abreviatura del ensayo, tanto para referirse al ensayo sobre el que están tratando como a otros ensayos que mencionen en su manuscrito.

\section{Preparación y envío del manuscrito}

\section{A. Cómo preparar un manuscrito para enviarlo a una revista biomédica}

Editores y revisores pasan mucho tiempo leyendo manuscritos y por ello agradecen que los manuscritos que reciben sean fáciles de leer y de editar. Gran parte de la información de las instrucciones que las revistas dan a los autores está diseñada para cumplir dicho objetivo, de manera que cumplan las necesidades editoriales específicas de cada revista. Las indicaciones que vienen a continuación proporcionan las directrices para la preparación de los manuscritos para su envío a cualquier revista.

\section{A.1.a. Principios generales}

El texto de los artículos sobre estudios observacionales y experimentales normalmente está dividido en los siguientes apartados: Introducción, Métodos, Resultados, y Discusión, aunque no necesariamente. Esta estructura, llamada "IMRYD" , no es un formato de publicación arbitrario, sino más bien el reflejo directo del proceso de investigación científica. Puede que los artículos largos necesiten subapartados, sobre todo en los Resultados y la Discusión, para aclarar su contenido. Otro tipo de artículos, como los informes de casos clínicos, las revisiones y los editoriales, probablemente necesiten otro tipo de formatos.

Los formatos electrónicos han creado la posibilidad de añadir detalles o apartados enteros, superponiendo información, creando enlaces o bien extrayendo una parte de un artículo, y otras cosas por el estilo. Los autores deben trabajar estrechamente con los editores para desarrollar o utilizar estos nuevos formatos de publicación, y deberían enviar el material para su revisión por pares pensando en eventuales formatos electrónicos suplementarios.

El espaciado doble de todas las partes del manuscrito incluyendo la portada, el resumen, el texto, los agradecimientos, las referencias, las tablas individuales y las leyendas- y unos márgenes generosos facilitan a editores y revisores editar el texto línea a línea y añadir comentarios y preguntas directamente sobre la copia en papel. Si los manuscritos se presentan en formato electrónico, los archivos deben estar a doble espacio, para facilitar la impresión del manuscrito para su evaluación y revisión.

Los autores deberían numerar todas las páginas del manuscrito de forma consecutiva, empezando por la portada, para facilitar la labor editorial. 
IV. A.1.b. Directrices para la presentación de estudios con diseños específicos

Los artículos de investigación a menudo omiten alguna información importante. Se han desarrollado pautas de redacción

(http://www.nlm.nih.gov/services/research_report guide.html) para un cierto número de modelos de investigación, y algunas revistas pueden recomendar a los autores que las sigan. Conviene que los autores consulten al respecto la Guía de Autores de su revista. Los requisitos generales listados en el próximo apartado se refieren a la redacción de los elementos esenciales para todos los tipos de diseño de estudios. Se anima a los autores a que consulten las pautas de redacción correspondientes a su propio diseño de investigación. Una buena fuente de pautas de redacción es el EQUATOR Network (http://equator-network.org/home).

\section{A.2. Portada}

La portada debe incluir la siguiente información:

1. El título del artículo. Los títulos concisos son más fáciles de leer que los largos o intrincados. Sin embargo, si los títulos son demasiado cortos pueden no ofrecer información importante, como el diseño del estudio (que es especialmente importante para identificar los ensayos controlados aleatorizados). Los autores deberían incluir en el título toda la información para que la recuperación electrónica del artículo sea a la vez sensible y específica.

2. Los nombres de los autores y sus afiliaciones institucionales. Algunas revistas publican la(s) máxima(s) titulación(es) académicas del autor mientras otras no lo hacen.

3. El nombre del/de los departamento(s) e instituciones a los que debe atribuirse el trabajo.

4. Descargos de responsabilidad, si los hay.

5. Información para contactar con el autor corresponsal (corresponding author). El nombre, dirección postal, números de teléfono y fax, y dirección electrónica del autor responsable de la correspondencia sobre el manuscrito; este autor puede o no ser el "garante" de la integridad del estudio en su conjunto, si es que se identifica a alguien con esta función. El autor corresponsal debe indicar claramente si puede publicarse o no su dirección electrónica.

6. El nombre y dirección del autor al que deben dirigirse las solicitudes de separatas, o una nota que diga que no podrán obtenerse separatas de los autores.

7. $\mathrm{La}(\mathrm{s})$ fuente(s) de ayuda en forma de becas, equipo, medicamentos o todas ellas.

8. Un encabezamiento de página o título abreviado del artículo. Algunas revistas piden un breve encabezamiento o pie de página que normalmente no debe superar los 40 caracteres (incluidos espacios). Los encabezamientos se publican en la mayoría de revistas, pero a veces también se usan en la editorial para archivar y localizar manuscritos.

9. Recuentos de palabras. El hecho de contar las palabras que forman parte del texto (excluyendo el resumen, los agradecimientos, las leyendas de las figuras y las referencias), permite que los editores y revisores decidan si la información contenida en el artículo justifica la cantidad de espacio que se le dedica o si el manuscrito presentado es adecuado teniendo en cuenta los límites de palabras de la revista. Por la misma razón, también es útil contar aparte las palabras del resumen. 
10. Número de figuras y tablas. Al personal de la editorial y a los revisores les resulta difícil decidir si las figuras y tablas que deberían haber acompañado al manuscrito están realmente incluidas, a menos que se anoten en la portada los números de las figuras y tablas que pertenecen al manuscrito.

\section{A.3. Declaración de conflictos de intereses}

Para evitar que se pase por alto o se traspapele la información sobre un posible conflicto de intereses de los autores, es necesario que esta información forme parte del manuscrito. El ICMJE ha desarrollado un modelo estándar de declaración (http://www.icmje.org/coi disclosure.pdf) para las revistas miembros del ICMJE. Se invita a que otras revistas adopten el mismo modelo. Cada revista puede diferir respecto al lugar donde den esta información, y, por otra parte, algunas revistas no envían información sobre conflictos de intereses a los revisores. (Véase sección II.D. Conflictos de intereses, p. 6).

\section{A.4. Resumen}

Para investigaciones originales y revisiones sistemáticas, lo ideal es un resumen estructurado. El resumen debe proporcionar el contexto o antecedentes del estudio y debe fijar los objetivos del mismo, los procedimientos básicos (selección de los sujetos o animales de laboratorio que han participado en el estudio, métodos de observación y métodos analíticos), los principales resultados (incluyendo, si es posible, la magnitud de los efectos y su significación estadística), las conclusiones principales y las fuentes de financiación. El resumen debería destacar aspectos nuevos e importantes o las observaciones que se derivan del estudio. Los artículos sobre ensayos clínicos deberían incluir resúmenes que incidieran en los puntos que el grupo CONSORT considera esenciales (http://www.consortstatement.org/?=1190).

Debido a que los resúmenes son la única parte esencial del artículo que está indexada en muchas bases de datos electrónicas, y la única parte que leen muchos lectores, los autores deben cuidar que los resúmenes reflejen con precisión el contenido del artículo. Desgraciadamente, muchos resúmenes no concuerdan con el texto del artículo. ${ }^{6}$ El formato requerido para los resúmenes estructurados difiere de una revista a otra, y algunas revistas utilizan más de un formato; los autores deben esforzarse por preparar sus resúmenes en el formato especificado por la revista elegida.

El ICMJE recomienda que las revistas publiquen el número de registro del ensayo al final del resumen. También recomienda que cuando se dispone de número de registro los autores mencionen este número la primera vez que usen la abreviatura del ensayo, tanto para referirse al ensayo sobre el que están tratando como a otros ensayos que mencionen en su manuscrito.

\section{A.5. Introducción}

En la introducción se debe expresar el contexto o los antecedentes del estudio (por ejemplo, la naturaleza del problema y su importancia) y enunciar el propósito específico u objetivo de la investigación o la hipótesis que se pone a prueba en el estudio u observación; a menudo la investigación se centra con más claridad cuando se plantea como pregunta. Tanto los objetivos principales como los secundarios deberían estar claros, y debería describirse cualquier análisis de 
subgrupos predefinido. Se deben incluir sólo las referencias que sean estrictamente pertinentes y no añadir datos o conclusiones del trabajo que se presenta.

\section{A.6. Métodos}

La sección de Métodos debe incluir solamente la información que estaba disponible cuando se redactó el plan o protocolo del estudio; toda la información que se obtiene durante el proceso del estudio debe figurar en la sección de Resultados.

\section{A.6.a. Selección y descripción de los participantes}

Describir claramente la selección de los sujetos objeto de observación o experimentación (pacientes o animales de laboratorio, incluyendo los controles), incluir los criterios de selección y exclusión, y dar una descripción de la población origen de los sujetos del estudio. Dado que no siempre está clara la importancia de variables como la edad y el sexo para el objetivo de la investigación, los autores deberían explicar su criterio cuando las incluyen en el estudio; por ejemplo, los autores deberían explicar por qué sólo se incluyeron individuos de ciertas edades o por qué se excluyeron las mujeres. El objetivo principal debe consistir en expresar claramente cómo y porqué se realizó el estudio de una forma determinada. Cuando los autores usan variables tales como la raza o la etnia, deberían definir cómo midieron estas variables y justificar su relevancia.

\section{A.6.b. Información técnica}

Identificar los métodos, aparatos (dar el nombre y la dirección del fabricante entre paréntesis), así como los procedimientos con suficiente detalle para permitir a otras personas reproducir los resultados. Dar las referencias de los métodos habituales, incluyendo los métodos estadísticos (véase más adelante); facilitar referencias y breves descripciones de los métodos que han sido publicados, pero que son poco conocidos; describir los métodos nuevos o sustancialmente modificados, dar las razones por las que se han usado y evaluar sus limitaciones. Identificar con precisión todos los medicamentos y sustancias químicas usadas, incluyendo los nombres genéricos, las dosis y las vías de administración.

Los autores que envían artículos de revisión deberían incluir un apartado donde describieran los métodos usados para localizar, seleccionar, extraer y sintetizar los datos. Estos métodos también se deberían sintetizar en el resumen.

\section{A.6.c. Estadística}

Describir los métodos estadísticos con suficiente detalle para permitir que un lector experto con acceso a los datos originales pueda comprobar los resultados que se presentan. Cuando sea posible, cuantificar los hallazgos y presentarlos con los indicadores de medida de error o de incertidumbre adecuados (como los intervalos de confianza). Evitar basarse únicamente en la comprobación de hipótesis estadísticas, como el uso de valores $\mathrm{P}$, que no dan información sobre la magnitud del efecto. Siempre que sea posible, las referencias sobre el diseño del estudio y los métodos estadísticos deberían corresponder a manuales o artículos clásicos (con los números de página incluidos). Definir también los términos estadísticos, abreviaturas y la mayoría de símbolos. Especificar el software utilizado. 


\section{A.7. Resultados}

Presentar los resultados siguiendo una secuencia lógica en el texto, tablas e ilustraciones, y destacando en primer lugar los hallazgos más importantes. No repetir en el texto los datos de las tablas o ilustraciones; resaltar o resumir sólo las observaciones más importantes. Los materiales extra o suplementarios y los detalles técnicos pueden situarse en un anexo donde se puedan consultar para no interrumpir la secuencia del texto; si no, pueden publicarse solamente en la versión electrónica de la revista.

Cuando los datos se resuman en el apartado Resultados, al ofrecer los resultados numéricos no sólo deben presentarse los derivados (por ejemplo, porcentajes), sino también los valores absolutos a partir de los cuales se calcularon, y especificar los métodos estadísticos utilizados para analizarlos. Limitar el número de tablas y figuras a las estrictamente necesarias para ilustrar el tema del artículo y para evaluar su grado de apoyo. Usar gráficos como alternativa a las tablas con muchas entradas; no duplicar datos en los gráficos y tablas. Evitar usos no técnicos de términos estadísticos, como "azar" (que implica un dispositivo de aleatorización), "normal," "significativo," "correlaciones" y "muestra."

Cuando sea científicamente adecuado, incluir análisis en función de variables como la edad y el sexo.

\section{A.8. Discusión}

Destacar los aspectos más novedosos e importantes del estudio y las conclusiones que de ellos se deducen, contextualizándolos en el conjunto de las evidencias más accesibles. No repetir en detalle datos u otro material que aparezca en la Introducción o en el apartado de Resultados. En el caso de estudios experimentales es útil empezar la discusión resumiendo brevemente los principales resultados; a continuación, explorar los posibles mecanismos o explicaciones de dichos hallazgos, comparar y contrastar los resultados con los de otros estudios relevantes, exponer las limitaciones del estudio, y explorar las implicaciones de los resultados para futuras investigaciones y para la práctica clínica.

Relacionar las conclusiones con los objetivos del estudio, evitando hacer afirmaciones rotundas y sacar conclusiones que no estén debidamente respaldadas por los datos. En particular, evitar afirmaciones sobre los costes y beneficios económicos a menos que el manuscrito incluya datos económicos con sus correspondientes análisis. Evitar afirmaciones o alusiones a aspectos de la investigación que no se hayan llevado a término. Cabe la posibilidad de establecer nuevas hipótesis cuando tengan base, pero calificándolas claramente como tales.

\section{A.9. Referencias bibliográficas}

\section{A.9.a. Consideraciones generales sobre las referencias}

Aunque las referencias bibliográficas en artículos de revisión puede ser una forma eficaz de conducir a los lectores a un corpus de literatura, no siempre reflejan de forma precisa el trabajo original. Por tanto, siempre que sea posible se deberían dar a los lectores las referencias directas de las fuentes originales de la investigación. Por otra parte, listas exhaustivas de referencias a obras originales sobre un tema determinado pueden malgastar demasiado espacio en una página. Con frecuencia,

http://scielo.sld.cu 
un pequeño número de referencias a los artículos originales clave tienen la misma utilidad que listas más exhaustivas, especialmente porque hoy en día pueden añadirse referencias a la versión electrónica de artículos publicados, y porque la búsqueda electrónica permite a los lectores recuperar estudios de forma eficiente.

Es recomendable no usar resúmenes como referencias. Las referencias a artículos ya aceptados pero todavía no publicados deberían citarse con la especificación "en prensa" o "de próxima aparición"; los autores deberían obtener una autorización escrita para citar dichos artículos, así como la confirmación de que han sido aceptados para ser publicados. La información de los manuscritos que han sido presentados pero no han sido aceptados debería citarse en el texto como "observaciones no publicadas" con el permiso escrito de la fuente.

Evitar citar una "comunicación personal" a menos que proporcione una información esencial no disponible en una fuente pública, y en este caso debe citarse en el texto, entre paréntesis, el nombre de la persona y la fecha de la comunicación. En los artículos científicos, obtener el permiso escrito y la confirmación de la exactitud de la propia fuente de una comunicación personal.

Algunas revistas comprueban la exactitud de todas las citas bibliográficas, pero no todas lo hacen, y a veces aparecen referencias erróneas en la versión publicada de los artículos. Para minimizar dichos errores, los autores deberían cotejar las referencias, ya sea usando una fuente bibliográfica electrónica, como, por ejemplo, PubMed, ya sea copias impresas de las fuentes originales. Los autores son responsables de comprobar que ninguna de las referencias corresponda a artículos retractados, excepto en caso de referirse a la retractación. Para los artículos publicados en revistas indexadas en MEDLINE, el ICMJE considera PubMed la fuente autorizada para información sobre retractaciones. Los autores pueden identificar en MEDLINE los artículos retractados mediante el uso del término de búsqueda Retracted publication [pt], en donde pt entre corchetes significa tipo de publicación en PubMed.

\section{A.9.b. Estilo y formato de una referencia}

El estilo de los Requisitos de Uniformidad, en lo que respecta a referencias, está basado en gran parte en un estilo del American National Standards Institute adaptado por la NLM para sus bases de datos. ${ }^{7}$ Para ejemplos de formato de referencias bibliográficas, los autores deberían consultar Citing Medicine de la NLM para información sobre formatos recomendados en una serie de tipos de referencia. Los autores pueden también consultar las referencias de muestra que figuran en una lista de ejemplos derivados o inspirados en Citing Medicine, de fácil uso por los seguidores del ICMJE. La NLM se ocupa del mantenimiento de estas referencias de muestra (véase Apéndice).

Las referencias deberían estar numeradas consecutivamente, siguiendo el orden en que se mencionan por vez primera en el texto. Identificar las referencias del texto, las tablas y las leyendas con números arábigos entre paréntesis. Las referencias que sólo se citan en tablas o en leyendas de figuras deben numerarse en función de la secuencia establecida por la primera identificación del texto de una tabla o figura concreta. Los títulos de las revistas deben abreviarse conforme se hace en la lista de Revistas Indexadas para MEDLINE, expuesta por la NLM en su página web (http://www.ncbi.nlm.nih.gov/journals).

Las revistas pueden pedir a los autores que citen las referencias electrónicas entre paréntesis en el texto o bien en referencias numeradas al final del texto. Los 
autores deberían consultar las normas de la revista a la que piensan presentar su trabajo.

\section{A.10. Tablas}

Las tablas recogen la información de forma concisa y la presentan de forma eficiente; ofrecen también la información con los grados de detalle y precisión deseados. La inclusión de datos en tablas y no en el texto permite reducir la extensión del mismo.

Mecanografiar o imprimir las tablas a doble espacio en una hoja aparte. Numerar las tablas consecutivamente siguiendo el orden de la primera cita que aparece en el texto y asignarles un escueto título. No usar líneas horizontales ni verticales. Cada columna debe ir encabezada por un título breve o abreviado. Los autores deben colocar las explicaciones en notas a pie de tabla, no en el título. Explicar en notas a pie de tabla todas las abreviaturas no habituales. Para las notas a pie de tabla, usar

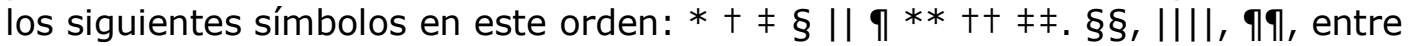
otras.

Identificar los índices de variabilidad, como la desviación estándar y el error estándar de la media.

Asegurarse de que en el texto cada tabla tiene su correspondiente cita.

Si se usan datos de otra fuente, ya sea publicada o no publicada, obtener el permiso correspondiente y hacer mención completa de estas fuentes.

Las tablas adicionales que contengan datos de apoyo demasiado extensos para ser publicados en la versión impresa, pueden publicarse en la versión electrónica de la revista, depositarse en un servicio de archivos, o ponerse a disposición de los lectores a través de los autores. Se añadirá al texto la información para comunicar a los lectores de que dichas tablas se hallan a su disposición y sobre el lugar donde está disponible. Es necesario presentar dichas tablas juntamente con el artículo para que estén a disposición de los revisores.

\section{A.11. Ilustraciones (figuras)}

Las figuras deberían haber sido diseñadas y fotografiadas en calidad profesional o bien presentadas como fotografías digitales. Además de solicitar una versión de las figuras adecuada para su impresión, algunas revistas piden a los autores los archivos electrónicos de las figuras en un formato determinado (por ejemplo, JPEG - GIF) que produzca imágenes de alta calidad en la versión web de la revista; los autores deberían revisar las imágenes de dichos archivos en una pantalla de ordenador antes de enviarlas, para asegurarse de que cumplen sus propios estándares de calidad.

Para radiografías, escáneres y otras imágenes de técnicas diagnósticas, así como para fotografías de imágenes de muestras patológicas o microfotografías, enviar fotografías nítidas y brillantes en blanco y negro o en color, normalmente de $127 \times$ $173 \mathrm{~mm}$. Aunque algunas revistas vuelven a dibujar las figuras, muchas no lo hacen. Las letras, números y símbolos de las figuras deberían ser claros y totalmente uniformes, y tener un tamaño suficiente para que al reducirlas para su publicación sigan siendo legibles. Las figuras deben ser tan claras como sea posible (autoexplicativas), ya que muchas se usarán directamente para las presentaciones 
de diapositivas. En las leyendas de las figuras no deberían faltar títulos ni explicaciones, pero estas explicaciones no deben figurar en el interior de las ilustraciones.

Las microfotografías deberían tener indicadores internos de escala. Los símbolos, flechas o letras usados en las microfotografías deberían contrastar con el fondo.

Las fotografías de personas potencialmente identificables deben ir acompañadas de la correspondiente autorización escrita para usarlas.

Las figuras deberían numerarse consecutivamente siguiendo el orden de primera aparición en el texto. Si se utiliza una figura ya previamente publicada, debe mencionarse la fuente original y presentar la autorización escrita del propietario del copyright para reproducir el material. El permiso es necesario independientemente del autor o de la editorial, excepto en el caso de documentos de dominio público.

Para las ilustraciones en color, comprobar si la revista pide negativos en color, transparencias o fotografías en color. El hecho de acompañarlas con dibujos que indiquen la zona que debe reproducirse puede facilitar la labor del editor. Algunas revistas publican ilustraciones en color sólo si el autor corre con los gastos suplementarios.

Los autores deberían consultar las revistas para conocer los requisitos que deben cumplir las figuras que se presentan en formato electrónico.

\section{A.12. Leyendas de las ilustraciones}

Mecanografiar o imprimir las leyendas de las ilustraciones a doble espacio, en una página aparte, numeradas con los números arábigos de las correspondientes ilustraciones. Cuando se usan símbolos, flechas, números o letras para identificar partes de las ilustraciones, deberán identificarse y explicarse claramente en la leyenda. Especificar la escala interna e identificar el método de coloración de las microfotografías.

\section{A.13. Unidades de medida}

Las medidas de longitud, altura, peso y volumen deberían darse en unidades métricas (metro, kilogramo o litro) o en los múltiplos o submúltiplos decimales.

Las temperaturas deberían expresarse en grados Celsius. La presión sanguínea debe medirse en milímetros de mercurio, a menos que la revista especifique otras unidades.

Para las medidas hematológicas, de química clínica, u otras, las revistas usan distintas unidades. Los autores deben consultar la información para autores de la revista concreta y dar los datos de laboratorio tanto en el sistema de unidades que usa la revista como en el Sistema Internacional de Unidades (SI).

Los editores pueden pedir a los autores, antes de la publicación, unidades alternativas o distintas a las del SI, cuando las unidades del SI no sean universalmente usadas. Las concentraciones de medicamentos pueden darse en SI o en unidades de masa, pero si es apropiado dar las dos, la medida alternativa debe escribirse entre paréntesis. 


\section{A.14. Abreviaturas y símbolos}

Usar solamente abreviaturas estándar; el uso de abreviaturas no estándar puede resultar extremadamente confuso para los lectores. Evitar el uso de abreviaturas en el título del manuscrito. La primera vez que se usa una abreviatura debería ir precedida por el término sin abreviar, seguido de la abreviatura entre paréntesis, a menos que sea una unidad de medida estándar.

\section{B Envío del manuscrito a la revista}

Actualmente un número creciente de revistas aceptan el envío electrónico de los manuscritos, ya sea en disquete, como documentos adjuntos de un correo electrónico, o bien descargándolos directamente en la página web de la revista. El envío electrónico ahorra tiempo y dinero, y permite su uso en formato electrónico a lo largo del proceso editorial (por ejemplo, cuando se envía para ser evaluado). Cuando se envía un manuscrito electrónicamente, los autores deberían consultar las instrucciones para autores de la revista.

Si se presenta una versión en papel del manuscrito, debe enviarse el número requerido de copias del manuscrito y de las figuras; todas ellas son necesarias para la evaluación y la edición, y no se puede suponer que el personal de la editorial va a ocuparse de realizar las copias.

Los manuscritos irán acompañados de una carta que debe incluir la siguiente información:

- Una declaración completa al editor de todos los manuscritos enviados para publicar y de los artículos previos que pudieran considerarse publicaciones redundantes del mismo trabajo o de un trabajo semejante. Cualquiera de estos trabajos debería tener una mención específica en carta, además de su referencia en el nuevo artículo. Junto con el manuscrito deben incluirse copias de este material que ayudarán al editor a decidir cómo afrontar la cuestión.

- Una declaración de las relaciones financieras o de otro tipo que puedan acarrear un conflicto de intereses, en caso de que esta información no esté incluida en el propio manuscrito o en el formulario de los autores.

- Una declaración donde se afirme que el manuscrito ha sido leído y aprobado por todos los autores, que se cumplen todos los requisitos de autoría tal y como han sido definidos en este documento, y que los autores consideran que el manuscrito presenta un trabajo honesto, en caso de que esta información no se forme parte de un formulario de la revista (véase más abajo).

- El nombre, la dirección y el número de teléfono del autor corresponsal, que es el responsable de comunicarse con los demás autores para comentar las revisiones y para la aprobación final de las pruebas de imprenta, en caso de que esta información no se incluya en el propio manuscrito.

La carta debe facilitar cualquier información adicional que pueda ser útil al editor, como por ejemplo a qué formato o tipo de artículo corresponde el manuscrito en cuestión. Si el manuscrito se ha presentado previamente a otra revista, es útil incluir los comentarios del editor y de los anteriores revisores junto con el manuscrito, así como las respuestas de los autores a estos comentarios. Los editores animan a los autores a presentar estas comunicaciones previas, ya que ello puede acelerar el proceso de evaluación. 
Actualmente muchas revistas facilitan una "lista de comprobación", previa al envío del manuscrito, donde se enumeran todos los elementos que deben presentarse y que ayuda al autor a asegurarse de que todos ellos se han incluido en el envío. Algunas revistas también piden a los autores que completen dichas listas para los artículos sobre ciertos tipos de estudios (por ejemplo, la lista del CONSORT para los artículos sobre ensayos controlados aleatorizados). Los autores deberían averiguar si la revista utiliza dichas listas y, si éste es el caso, enviarlas con el manuscrito.

El manuscrito debe ir acompañado de una copia de las autorizaciones para reproducir material ya previamente publicado, para usar ilustraciones previamente publicadas, para dar a conocer información sobre personas identificables, así como para mencionar a determinadas personas y agradecerles sus contribuciones.

\section{Referencias}

A. Referencias citadas en este documento

1. Davidoff F para el CSE Task Force on Authorship. Who's the Author? Problems with Biomedical Authorship, and Some Possible Solutions. Science Editor. JulyAugust 2000;23(4):111-119.

2. Yank V, Rennie D. Disclosure of researcher contributions: a study of original research articles en The Lancet. Ann Intern Med. 1999;Abr 20;130(8):661-70.

3. Flanagin A, Fontanarosa PB, DeAngelis CD. Authorship for research groups. JAMA. 2002;288:3166-68.

4. Godlee F, Jefferson T. Peer Review in Health Sciences. London: BMJ Books; 1999.

5. http://www.wma.net/e/policy/b3.htm (comprobado 26 de junio 2009).

6. Rochon PA, Gurwitz JH, Cheung CM, Hayes JA, Chalmers TC. Evaluating the quality of articles published in journal supplements compared with the quality of those published in the parent journal. JAMA. 1994;272:108-13.

7. Pitkin RM, Branagan MA, Burmeister LF. Accuracy of data in abstracts of published research articles. JAMA. 1999 Mar 24-31;281(12):1110-1.

B. Otras fuentes de información relacionadas con revistas biomédicas

World Association of Medical Editors (WAME)

Council of Science Editors (CSE)

European Association of Science Editors (EASE)

Cochrane Collaboration

Committee on Publication Ethics

EQUATOR NETWORK http://www.equator-network.org 


\section{Sobre el Comité Internacional de Editores de Revistas Biomédicas}

El Comité Internacional de Editores de Revistas Biomédicas (ICMJE) es un grupo de editores de revistas de medicina general cuyos miembros se reúnen anualmente y consolidan su trabajo con los Requisitos de Uniformidad de los manuscritos. El ICMJE acepta comentarios sobre este documento y sugerencias para el desarrollo de otros aspectos en el futuro.

\section{Autores de los Requisitos de Uniformidad}

Las revistas y organismos participantes en el ICMJE, que aprobaron la revisión de los Requisitos de Uniformidad de los manuscritos en Abril de 2010, son: Annals of Internal Medicine, British Medical Journal, Canadian Medical Association Journal, China Medical Journal, Croatian Medical Journal, Journal of the American Medical Association, The Dutch Medical Journal (Nederlands Tijdschrift voor Geneeskunde), New England Journal of Medicine, New Zealand Medical Journal, The Lancet, The Medical Journal of Australia, Revista Médica de Chile, Tidsskrift for Den Norske Laegeforening, Journal of the Danish Medical Association (Ugeskrift for Laeger), la National Library of Medicine de los EE.UU., y la World Association of Medical Editors.

\section{Uso, distribución y traducción de los Requisitos de Uniformidad}

Los usuarios pueden imprimir, copiar y distribuir este documento sin cargo alguno y con propósitos educativos y no lucrativos. EI ICMJE no suministra ejemplares (separatas) de este documento.

La política del ICMJE es que las organizaciones interesadas faciliten el enlace con el documento oficial en inglés en http://www.ICMJE.org. El ICMJE no aprueba la publicación del documento oficial en inglés en otros sitios web distintos de http://www.ICMJE.org.

EI ICMJE invita a las organizaciones a que reproduzcan o traduzcan este documento a otras lenguas distintas del inglés con propósitos no lucrativos. Sin embargo, el ICMJE no dispone de los recursos necesarios para traducir ni para revisar ni para aprobar las versiones reproducidas o traducidas de este documento. Así pues, cualquier traducción debería incluir en un lugar destacado la siguiente frase: "Reimpresión o traducción al (insertar el nombre del idioma) del ICMJE Uniform Requirements for Manuscripts Submitted to Biomedical Journals. La (insertar el nombre de la organización) ha realizado esta traducción con la ayuda de (incluir nombre del patrocinador, si lo hay). El ICMJE no ha revisado ni aprobado el contenido de esta reimpresión o traducción. El ICMJE revisa periódicamente los Requisitos de Uniformidad y por lo tanto puede que esta reimpresión/traducción preparada en (insertar fecha) no refleje fielmente la versión oficial vigente, que se halla en http://www.ICMJE.org. La versión oficial de los Requisitos de Uniformidad de Manuscritos enviados a Revistas Biomédicas se encuentra en http://www.ICMJE.org."

No exigimos a los particulares ni a las organizaciones que reproduzcan o traduzcan los Requisitos de Uniformidad para manuscritos enviados a revistas biomédicas la obtención de un permiso formal por escrito del ICMJE. Sin embargo, el ICMJE pide que dichos particulares u organizaciones notifiquen a la secretaría del ICMJE la existencia de tal reproducción o traducción a fin de que el ICMJE pueda disponer de un registro de estas versiones del documento.

http://scielo.sld.cu 


\section{Preguntas}

Antes de formular una pregunta consulte la FAQ del ICMJE

(http://www.icmje.org/faq clinical.html) ya que en esta página se da respuesta a las preguntas más habituales.

Las preguntas sobre los Requisitos de Uniformidad deben dirigirse a la oficina del secretariado de la ICMJE usando el vínculo contact ICMJE en la página http://www.icmje.org. Por favor, no dirijan a la secretaría del ICMJE preguntas sobre un estudio en particular, sobre el estilo de una determinada revista, o sobre las políticas de una revista en concreto. EI ICMJE no guarda en sus archivos información de contacto con las revistas. Los originales que se pretendan enviar a una revista deben enviarse directamente a la revista, no al ICMJE.

\section{APÉNDICE}

\section{Requisitos de uniformidad para manuscritos enviados a revistas biomédicas: Ejemplos de referencias}

Actualizado el 27 de Julio de 2010

Comité Internacional de Editores de Revistas Médicas (ICMJE)

Biblioteca Nacional de Medicina de los EE. UU. (NLM)

Versión oficial en inglés:

http://www.nlm.nih.gov/bsd/uniform requirements.html

\section{Artículos de Revistas}

\section{Artículo estándar}

Mencionar los seis primeros autores, seguidos de "et al."

(Nota: La NLM lista actualmente todos los autores)

Halpern SD, Ubel PA, Caplan AL. Solid-organ transplantation in HIV-infected patients. N Engl J Med. 2002 Jul 25;347(4):284-7.

Si la revista mantiene el criterio de paginación continua a lo largo de todo el volumen (como hacen muchas revistas médicas), opcionalmente se puede omitir el mes y el número.

Halpern SD, Ubel PA, Caplan AL. Solid-organ transplantation in HIV-infected patients. N Engl J Med. 2002;347:284-7.

http://scielo.sld.cu 
Más de seis autores:

Rose ME, Huerbin MB, Melick J, Marion DW, Palmer AM, Schiding JK, et al. Regulation of interstitial excitatory amino acid concentrations after cortical contusion injury. Brain Res. 2002;935(1-2):40-6.

Si el artículo tiene un identificador único en una base de datos, opcionalmente se puede añadir:

Halpern SD, Ubel PA, Caplan AL. Solid-organ transplantation in HIV-infected patients. N Engl J Med. 2002 Jul 25;347(4):284-7. PubMed; PMID 12140307.

Forooghian F, Yeh S, Faia LJ, Nussenblatt RB. Uveitic foveal atrophy: clinical features and associations. Arch Ophthalmol. 2009 Feb;127(2):179-86. PubMed PMID: 19204236; PubMed Central PMCID: PMC2653214.

Incluir adicionalmente el número de registro de un ensayo clínico:

Trachtenberg F, Maserejian NN, Soncini JA, Hayes C, Tavares M. Does fluoride in compomers prevent future caries in children? J Dent Res. 2009 Mar;88(3):276-9. PubMed PMID: 19329464 . ClinicalTrials.gov registration number: NCT00065988.

\section{Autor colectivo (el autor es un equipo)}

Diabetes Prevention Program Research Group. Hypertension, insulin, and proinsulin in participants with impaired glucose tolerance. Hypertension. 2002;40(5):679-86.

\section{Autoría compartida entre autores individuales y un equipo}

(Listar todos tal como aparecen en el articulo)

Vallancien G, Emberton M, Harving N, van Moorselaar RJ; Alf-One Study Group. Sexual dysfunction in 1,274 European men suffering from lower urinary tract symptoms. J Urol. 2003;169(6):2257-61.

Margulies EH, Blanchette M; NISC Comparative Sequencing Program, Haussler D, Green ED. Identification and characterization of multi-species conserved sequences. Genome Res. 2003 Dec;13(12):2507-18.

\section{No se menciona el autor}

21st century heart solution may have a sting in the tail. BMJ. 2002;325(7357):184.

\section{Artículo en un idioma distinto del inglés}

Ellingsen $A E$, Wilhelmsen I. Sykdomsangst blant medisin- og jusstudenter. Tidsskr Nor Laegeforen. 2002;122(8):785-7. Norwegian.

Traducción opcional del título del artículo (práctica llevada a cabo en MEDLINE/Plumbed): 
Ellingsen $A E$, Wilhelmsen I. [Disease anxiety among medical students and law students]. Tidsskr Nor Laegeforen. 2002 Mar 20;122(8):785-7. Norwegian.

\section{Suplemento de un volumen}

Geraud G, Spierings EL, Keywood C. Tolerability and safety of frovatriptan with short- and long-term use for treatment of migraine and in comparison with sumatriptan. Headache. 2002;42 Suppl 2:S93-9.

\section{Suplemento de un número}

Glauser TA. Integrating clinical trial data into clinical practice. Neurology. 2002;58(12 Suppl 7):S6-12.

\section{Parte de un volumen}

Abend SM, Kulish N. The psychoanalytic method from an epistemological viewpoint. Int J Psychoanal. 2002;83(Pt 2):491-5.

\section{Parte de un número}

Ahrar K, Madoff DC, Gupta S, Wallace MJ, Price RE, Wright KC. Development of a large animal model for lung tumors. J Vasc Interv Radiol. 2002;13(9 Pt 1):923-8.

\section{Número sin volumen}

Banit DM, Kaufer $\mathrm{H}$, Hartford JM. Intraoperative frozen section analysis in revision total joint arthroplasty. Clin Orthop. 2002;(401):230-8.

\section{Sin volumen ni número}

Outreach: bringing HIV-positive individuals into care. HRSA Careaction. 2002 Jun:1-6.

\section{Páginas en números romanos}

Chadwick R, Schuklenk U. The politics of ethical consensus finding. Bioethics. 2002;16(2):iii-v.

\section{Indicación del tipo de artículo cuando sea necesario}

Tor $\mathrm{M}$, Turker $\mathrm{H}$. International approaches to the prescription of long-term oxygen therapy [letter]. Eur Respir J. 2002;20(1):242.

(N. del T.: En español [carta]) 
Lofwall MR, Strain EC, Brooner RK, Kindbom KA, Bigelow GE. Characteristics of older methadone maintenance (MM) patients [abstract]. Drug Alcohol Depend. 2002;66 Suppl 1:S105.

(N. del T.: En español [resumen])

\section{Artículo que contiene una retractación}

Feifel D, Moutier CY, Perry W. Safety and tolerability of a rapidly escalating doseloading regimen for risperidone. J Clin Psychiatry. 2002;63(2):169. Retraction of: Feifel D, Moutier CY, Perry W. J Clin Psychiatry. 2000;61(12):909-11.

(N. del T.: En español: Retractación de:)

Artículo que contiene una retractación parcial

Starkman JS, Wolder CE, Gomelsky A, Scarpero HM, Dmochowski RR. Voiding dysfunction after removal of eroded slings. J Urol. 2006 Dec;176(6 Pt 1):2749. Partial retraction of: Starkman JS, Wolter C, Gomelsky A, Scarpero HM, Dmochowski RR. J Urol. 2006 Sep;176(3):1040-4.

\section{Artículo objeto de retractación}

Feifel D, Moutier CY, Perry W. Safety and tolerability of a rapidly escalating doseloading regimen for risperidone. J Clin Psychiatry. 2000;61(12):909-11. Retraction in: Feifel D, Moutier CY, Perry W. J Clin Psychiatry. 2002;63(2):169. (N. del T.: En español: Retractación en:)

\section{Artículo parcialmente retractado}

Starkman JS, Wolter C, Gomelsky A, Scarpero HM, Dmochowski RR. Voiding dysfunction following removal of eroded synthetic mid urethral slings. J Urol. 2006 Sep;176(3):1040-4. Partial retraction in: Starkman JS, Wolder CE, Gomelsky A, Scarpero HM, Dmochowski RR. J Urol. 2006 Dec;176(6 Pt 1):2749.

\section{Artículo reeditado con correcciones}

Mansharamani M, Chilton BS. The reproductive importance of P-type ATPases. Mol Cell Endocrinol. 2002;188(1-2):22-5. Corrected and republished from: Mol Cell Endocrinol. 2001;183(1-2):123-6. (N. del T.: En español: Corregido y vuelto a publicar a partir de:)

\section{Artículo sobre el que se ha publicado una fe de erratas}

Malinowski JM, Bolesta S. Rosiglitazone in the treatment of type 2 diabetes mellitus: a critical review. Clin Ther. 2000;22(10):1151-68; discussion 1149-50. Erratum in: Clin Ther 2001;23(2):309. (N. del T.: En español: Fe de erratas en:) 


\section{Artículo publicado en formato electrónico antes que en versión impresa}

Yu WM, Hawley TS, Hawley RG, Qu CK. Immortalization of yolk sac-derived precursor cells. Blood. 2002 Nov 15;100(10):3828-31. Epub 2002 Jul 5. (N. del T.: En español: Publicación electrónica 5 Jul 2002)

\section{Libros y otras Monografías}

\section{Autores individuales}

Murray PR, Rosenthal KS, Kobayashi GS, Pfaller MA. Medical microbiology. 4th ed. St. Louis: Mosby; 2002.

\section{Editor(es), Compilador(es)}

Gilstrap LC 3rd, Cunningham FG, VanDorsten JP, editors. Operative obstetrics. 2nd ed. New York: McGraw-Hill; 2002. (N. del T.: En español: editores)

\section{Autor(es) y editor(es)}

Breedlove GK, Schorfheide AM. Adolescent pregnancy. 2nd ed. Wieczorek RR, editor. White Plains (NY): March of Dimes Education Services; 2001.

\section{Organización(es) como autor}

Royal Adelaide Hospital; University of Adelaide, Department of Clinical Nursing. Compendium of nursing research and practice development, 1999-2000. Adelaide (Australia): Adelaide University; 2001.

American Occupational Therapy Association, Ad Hoc Committee on Occupational Therapy Manpower. Occupational therapy manpower: a plan for progress. Rockville (MD): The Association; 1985 Apr. 84 p.

National Lawyer's Guild AIDs Network (US); National Gay Rights Advocates (US). AIDS practice manual: a legal and educational guide. 2nd ed. San Francisco: The Network; 1988.

\section{Capítulo de libro}

Meltzer PS, Kallioniemi A, Trent JM. Chromosome alterations in human solid tumors. In: Vogelstein B, Kinzler KW, editors. The genetic basis of human cancer. New York: McGraw-Hill; 2002. p. 93-113. (N. del T.: En español: En:)

\section{Actas de conferencias}

Harnden P, Joffe JK, Jones WG, editors. Germ cell tumours V. Proceedings of the 5th Germ Cell Tumour Conference; 2001 Sep 13-15; Leeds, UK. New York: Springer; 2002. (N. del T.: En español: Actas del/de la) 


\section{Artículo con el contenido de una conferencia}

Christensen S, Oppacher F. An analysis of Koza's computational effort statistic for genetic programming. In: Foster JA, Lutton E, Miller J, Ryan C, Tettamanzi AG, editors. Genetic programming. EuroGP 2002: Proceedings of the 5th European Conference on Genetic Programming; 2002 Apr 3-5; Kinsdale, Ireland. Berlin: Springer; 2002. p. 182-91. (N. del T.: En español: Actas del/de la)

\section{Informe científico o técnico}

Publicado por la entidad financiadora/patrocinadora:

Yen GG (Oklahoma State University, School of Electrical and Computer Engineering, Stillwater, OK). Health monitoring on vibration signatures. Final report. Arlington (VA): Air Force Office of Scientific Research (US), Air Force Research Laboratory; 2002 Feb. Report No.: AFRLSRBLTR020123. Contract No.: F496209810049.

Publicado por la entidad que lo realiza:

Russell ML, Goth-Goldstein R, Apte MG, Fisk WJ. Method for measuring the size distribution of airborne Rhinovirus. Berkeley (CA): Lawrence Berkeley National Laboratory, Environmental Energy Technologies Division; 2002 Jan. Report No.: LBNL49574. Contract No.: DEAC0376SF00098. Sponsored by the Department of Energy.

\section{Tesis}

Borkowski MM. Infant sleep and feeding: a telephone survey of Hispanic Americans [dissertation]. Mount Pleasant (MI): Central Michigan University; 2002. (N. del T.: En español: [tesis])

\section{Patente}

Pagedas AC, inventor; Ancel Surgical R\&D Inc., assignee. Flexible endoscopic grasping and cutting device and positioning tool assembly. United States patent US 20020103498. 2002 Aug 1. (N. del T.: En español: Patente de los EE. UU. ... 2002 Ago 1.)

\section{Otros tipos de publicaciones}

\section{Artículo de periódico}

Tynan T. Medical improvements lower homicide rate: study sees drop in assault rate. The Washington Post. 2002 Aug 12;Sect. A:2 (col. 4). (N. del T.: En español: 12 Ago 2002; Secc.) 


\section{Material audiovisual}

Chason KW, Sallustio S. Hospital preparedness for bioterrorism [videocassette]. Secaucus (NJ): Network for Continuing Medical Education; 2002. (N. del T.: En español: [videocinta])

\section{Documentos legales}

\section{Leyes:}

Veterans Hearing Loss Compensation Act of 2002, Pub. L. No. 107-9, 115 Stat. 11 (May 24, 2001).

Proyecto de ley no promulgado:

Healthy Children Learn Act, S. 1012, 107th Cong., 1st Sess. (2001).

Código de legislación Federal:

Cardiopulmonary Bypass Intracardiac Suction Control, 21 C.F.R. Sect. 870.4430 (2002).

\section{Jurisprudencia:}

Arsenic in Drinking Water: An Update on the Science, Benefits and Cost: Hearing Before the Subcomm. on Environment, Technology and Standards of the House Comm. on Science, 107th Cong., 1st Sess. (Oct. 4, 2001).

\section{Mapa}

Pratt B, Flick P, Vynne C, cartographers. Biodiversity hotspots [map]. Washington: Conservation International; 2000.

\section{Diccionarios y similares}

Dorland's illustrated medical dictionary. 29th ed. Philadelphia: W.B. Saunders; 2000. Filamin; p. 675.

\section{Trabajos no publicados}

\section{En prensa}

(Nota: La NLM prefiere el término "De próxima aparición" (Forthcoming) en lugar de "En prensa" (In press) porque no todos los artículos serán impresos.) Tian D, Araki $\mathrm{H}$, Stahl E, Bergelson J, Kreitman M. Signature of balancing selection in Arabidopsis. Proc Natl Acad Sci U S A. Forthcoming 2002. (N. del T.: En español: De próxima aparición) 


\section{Material electrónico}

\section{CD-ROM}

Anderson SC, Poulsen KB. Anderson's electronic atlas of hematology [CD-ROM]. Philadelphia: Lippincott Williams \& Wilkins; 2002.

\section{Artículo de revista en Internet}

Abood S. Quality improvement initiative in nursing homes: the ANA acts in an advisory role. Am J Nurs [Internet]. 2002 Jun [cited 2002 Aug 12];102(6):[about 1 p.]. Available from: http://www.nursingworld.org/AJN/2002/june/Wawatch.htmArticle (N. del T.: En español: [citado 12 Ago 2002]; [aprox. 1 p.]. Disponible en:)

Presentación opcional (se omite la frase entre corchetes que califica el título abreviado de la revista):

Abood S. Quality improvement initiative in nursing homes: the ANA acts in an advisory role. Am J Nurs. 2002 Jun [cited 2002 Aug 12];102(6):[about 1 p.]. Available from: http://www.nursingworld.org/AJN/2002/june/Wawatch.htmArticle

Artículo publicado en Internet antes que la edición impresa: Ver \# 18 (p. 27).

\section{Optional formats used by NLM in MEDLINE/PubMed:}

Artículo con el número de documento en lugar de la paginación tradicional: Williams JS, Brown SM, Conlin PR. Videos in clinical medicine. Blood-pressure measurement. N Engl J Med. 2009 Jan 29;360(5):e6. PubMed PMID: 19179309.

Artículo con el Identificador digital del objeto (Digital Object Identifier, DOI):

Zhang M, Holman CD, Price SD, Sanfilippo FM, Preen DB, Bulsara MK. Comorbidity and repeat admission to hospital for adverse drug reactions in older adults:

retrospective cohort study. BMJ. 2009 Jan 7;338:a2752. doi: 10.1136/bmj.a2752. PubMed PMID: 19129307; PubMed Central PMCID: PMC2615549.

Artículo con el Identificador de artículo del editor (publisher item identifier, pii) en lugar de la paginación tradicional o el DOI:

Tegnell A, Dillner J, Andrae B. Introduction of human papillomavirus (HPV) vaccination in Sweden. Euro Surveill. 2009 Feb 12;14(6). pii: 19119. PubMed PMID: 19215721.

\section{Monografía en Internet}

Foley $\mathrm{KM}$, Gelband $\mathrm{H}$, editors. Improving palliative care for cancer [Internet]. Washington: National Academy Press; 2001 [cited 2002 Jul 9]. Available from: http://www.nap.edu/books/0309074029/html/. (N. del T.: En español: [citado 9 Jul 2002]. Disponible en:) 


\section{Página principal de un sitio Web}

Cancer-Pain.org [Internet]. New York: Association of Cancer Online Resources, Inc.; c2000-01 [updated 2002 May 16; cited 2002 Jul 9]. Available from: http://www.cancer-pain.org/ . (N. del T.: En español: citado 9 Jul 2002]. Disponible en:)

\section{Página Web de un sitio Web}

American Medical Association [Internet]. Chicago: The Association; c1995-2002 [updated 2001 Aug 23; cited 2002 Aug 12]. AMA Office of Group Practice Liaison; [about 2 screens]. Available from: http://www.amaassn.org/ama/pub/category/1736.html (N. del T.: En español: [actualizado 23 Ago 2001; citado 12 Ago 2002]. [aprox. 2 pantallas]. Disponible en:)

\section{Base de datos en Internet}

Base de datos abierta (se actualiza):

Who's Certified [Internet]. Evanston (IL): The American Board of Medical Specialists. c2000 - [cited 2001 Mar 8]. Available from: http://www.abms.org/newsearch.asp (N. del T.: En español: [citado 8 Mar 2001]. Disponible en:)

Base de datos cerrada (no se actualiza):

Jablonski S. Online Multiple Congenital Anomaly/Mental Retardation (MCA/MR) Syndromes [database on the Internet]. Bethesda (MD): National Library of Medicine (US). c1999 [updated 2001 Nov 20; cited 2002 Aug 12]. Available from: http://www.nlm.nih.gov/mesh/jablonski/ syndrome title.html (N. del T.: En español: [actualizado 20 Nov 2001; citado 12 Ago 2002]. Disponible en:)

\section{Parte de una base de datos en Internet}

MeSH Browser [Internet]. Bethesda (MD): National Library of Medicine (US); 2002. Meta-analysis [cited 2008 Jul 24]; [about 2 p.]. Available from:

http://www.nlm.nih.gov/cgi/mesh/2008/MB cgi?mode $=$ \&index $=16408 \& v i e w=$ conc ept MeSH Unique ID: D017418. (N. del T.: En español: [citado 24 Jul 2008].

[aprox. 2 p.]. Disponible en:)

\section{Blogs}

Holt M. The Health Care Blog [Internet]. San Francisco: Matthew Holt. 2003 Oct[cited 2009 Feb 13]. Available from: http://www.thehealthcareblog.com/the health care blog/

KidneyNotes.com [Internet]. New York: KidneyNotes. c2006 - [cited 2009 Feb 13]. Available from: http://www.kidneynotes.com/ 
Wall Street Journal. HEALTH BLOG: WSJ's blog on health and the business of health [Internet]. Hensley S, editor. New York: Dow Jones \& Company, Inc. c2007 - [cited 2009 Feb 13]. Available from: http://blogs.wsj.com/health/

\section{Contribución a un Blog:}

Mantone J. Head trauma haunts many, researchers say. 2008 Jan 29 [cited 2009 Feb 13]. In: Wall Street Journal. HEALTH BLOG [Internet]. New York: Dow Jones \& Company, Inc. c2008 - [about 1 screen]. Available from:

http://blogs.wsj.com/health/2008/01/29/head-trauma-haunts-many-researchers-say/

Campbell A. Diabetes and alcohol: do the two mix? (Part 2). 2008 Jan 28 [cited 2009 Feb 13]. In: Diabetes Self-Management Blog [Internet]. New York: Diabetes Self-Management. [2006 Aug 14] - 2 p. Available from:

http://www.diabetesselfmanagement.com/blog LAmy Campbell/Diabetes and Alcohol Do the Two Mix Part 2.

Reider J. Docnotes: Health, Technology, Family Medicine and other observations [Internet]. [place unknown]: Jacob Reider. 1999 - CRP again ...; 2004 Apr 2 [cited 2009 Feb 13]; [about 1 screen]. Available from:

http://www.docnotes.com/2004/04/crp-again.html

Información más detallada de cómo citar referencias se puede encontrar en Citing Medicine (http://www.ncbi.nlm.nih.gov/books/bookres.fcgi/citmed/frontpage.html). Nota: el Appendix F de Citing Medicine indica de qué forma difieren las citas en MEDLINE/PubMed de las recomendadas en Citing Medicine. 